NBER WORKING PAPER SERIES

\title{
ESTIMATING MACROECONOMIC MODELS OF FINANCIAL CRISES: AN ENDOGENOUS REGIME-SWITCHING APPROACH
}

\author{
Gianluca Benigno \\ Andrew Foerster \\ Christopher Otrok \\ Alessandro Rebucci \\ Working Paper 26935 \\ http://www.nber.org/papers/w26935
NATIONAL BUREAU OF ECONOMIC RESEARCH
1050 Massachusetts Avenue
Cambridge, MA 02138
April 2020

We are grateful to Yan Bai, Dario Caldara, Pablo Guerron-Quintana, Giorgio Primiceri, Felipe Saffie, and Frank Schorfheide for helpful comments and discussions. We also thank participants at the NASMES, the SED, the EABCN-CEPR EUI Conf., the CEF, the Taipei Conf. on Growth, Trade and Dynamics, the CEPR ESSIM, the NBER Meeting on Methods and Applications for DSGE Models, the Midwest Macro Meetings, the Norges Bank Workshop on Nonlinear Models, the NBER Summer Institute, and the NBER IFM Spring Meeting, as well as seminar participants at Beijing Univ., Central Florida, ECB, Fudan Univ., Indiana, Notre Dame, Texas A\&M, KU Leuven, JHU Carey Business School, the Central Bank of Belgium, the ECB, and the Dallas and San Francisco Feds. Sanha Noh provided outstanding research assistance. The authors gratefully acknowledge financial support from NSF Grant SES1530707 and the Johns Hopkins Catalyst Award. The views expressed are solely those of the authors and do not necessarily reflect the views of the Federal Reserve Banks of New York, San Francisco, or St. Louis, the Federal Reserve System, or the National Bureau of Economic Research.

NBER working papers are circulated for discussion and comment purposes. They have not been peer-reviewed or been subject to the review by the NBER Board of Directors that accompanies official NBER publications.

(C) 2020 by Gianluca Benigno, Andrew Foerster, Christopher Otrok, and Alessandro Rebucci. All rights reserved. Short sections of text, not to exceed two paragraphs, may be quoted without explicit permission provided that full credit, including $(\subset)$ notice, is given to the source. 
Estimating Macroeconomic Models of Financial Crises: An Endogenous Regime-Switching Approach

Gianluca Benigno, Andrew Foerster, Christopher Otrok, and Alessandro Rebucci

NBER Working Paper No. 26935

April 2020

JEL No. C11,E30,F41,G01

\begin{abstract}
We estimate a workhorse DSGE model with an occasionally binding borrowing constraint. First, we propose a new specification of the occasionally binding constraint, where the transition between the unconstrained and constrained states is a stochastic function of the leverage level and the constraint multiplier. This specification maps into an endogenous regime-switching model. Second, we develop a general perturbation method for the solution of such a model. Third, we estimate the model with Bayesian methods to fit Mexico's business cycle and financial crisis history since 1981 . The estimated model fits the data well, identifying three crisis episodes of varying duration and intensity: the Debt Crisis in the early-1980s, the Peso Crisis in the mid-1990s, and the Global Financial Crisis in the late-2000s. The crisis episodes generated by the estimated model display sluggish and long-lasting build-up and stagnation phases driven by plausible combinations of shocks. Different sets of shocks explain different variables over the business cycle and the three historical episodes of sudden stops identified.
\end{abstract}

Gianluca Benigno

Department of Economics

London School of Economics

WC2A $2 \mathrm{AE}$

London WC2A 2AE

United Kingdom

and International Research Function, Federal Reserve Bank of New York

g.benigno@1se.ac.uk

Andrew Foerster

Federal Reserve Bank of San Francisco

101 Market St

San Francisco, CA 94105

andrew.foerster@sf.frb.org
Christopher Otrok

Department of Economics

University of Missouri

Columbia, MO 65211

and Federal Reserve Bank of St Louis

otrokc@missouri.edu

Alessandro Rebucci

Johns Hopkins Carey Business School

100 International Drive

Baltimore, MD 21202

and NBER

arebucci@jhu.edu 


\section{Introduction}

The Global Financial Crisis triggered strong renewed interest in understanding the causes, consequences, and remedies of financial crises. In this context, dynamic stochastic general equilibrium (DSGE) models with occasionally binding frictions proved successful as laboratories to study the anatomy of both business cycles and crises, and to explore optimal policy responses to these dynamics. This success is because occasionally binding financial frictions are mechanisms that create amplification of regular business cycle dynamics. For example, even in the case of the COVID-19 crisis, which did not originate in the financial sector, suddenly binding financial frictions powerfully amplified the initial impulse. Structural estimation of these models is challenging, yet important for inference on key parameters governing financial frictions, counterfactual policy analysis, and structural real-time forecasts.

In this paper, we structurally estimate a model with an occasionally binding borrowing constraint. We make three main contributions. First, we propose a new specification of the occasionally binding collateral constraint. Second, we develop a perturbation solution method suitable for solving models like ours in a way that permits likelihood-based estimation. Third, we focus on one particular type of crisis, the so-called sudden stop in international capital flows, and apply the proposed approach to the estimation of a medium-scale workhorse DSGE model of such crises, investigating sources and frictions of business cycles and crises in Mexico since 1981.

As a first step, we propose a new formulation of occasionally binding constraint models. As in models with constraints written as inequalities, our set up has two states or regimes: in the first, limited leverage amplifies regular shocks and gives rise to financial crises episodes; in the second, access to financing is unconstrained and the economy displays regular business cycles. In our specification, however, the transitions between the two regimes depend on a range rather than a unique level of leverage, with endogenous probabilities that depend on the borrowing capacity and the multiplier associated with the leverage constraint. This formulation maps the model with an occasionally binding leverage constraint into an endogenous regimeswitching model. The paper focuses on a particular friction and type of crisis, the so called sudden stop in capital flows, but the proposed specification has broader applicability to other types of occasionally binding constraints.

Next, we develop a perturbation-based solution method for solving the endoge- 
nous regime-switching model. The perturbation method is fast enough to permit likelihood-based estimation, is readily scalable to models larger than the one we estimate in this paper, and displays typical levels of accuracy. We also show analytically that to capture the effects of endogenous transition probabilities on the policy functions characterizing optimal behavior, and hence precautionary behavior, it is necessary to approximate the model solution at least to second-order, and that these effects would be missed by linear approximations. As with our first contribution, the solution method that we develop can be used with a wide range of endogenous regime-switching models.

Finally, we apply our borrowing constraint specification and solution method, and perform Bayesian estimation of a workhorse small open-economy model to characterize both financial crises and business cycles in Mexico. While our application focuses on an emerging market economy, our specification can be applied to the formulation and estimation of other model settings with occasionally binding constraints. For example, the approach that we propose could be applied to the formulation and estimation of models of occasionally binding credit frictions, housing constraints, banking with asymmetric information, downward wage rigidity, the zero lower bound, or a SIRmacro model in which the probability of being infected depends on agents' decisions as in Eichenbaum et al. (2020).

Figure 1 plots two critical variables in our application to Mexico: the current account balance as a share of GDP and the quarterly real GDP growth in deviation from sample mean. The figure illustrates the regular fluctuations in the data as well as multiple episodes of large current account reversals and persistent output growth declines. Large current account reversals and output drops of heterogeneous size and persistence are the two main empirical features commonly associated with sudden stops in capital flows, not only in Mexico but also in many other emerging markets exposed to volatile capital flows. In this paper, we focus on the challenge of fitting a structural model to Mexico's business cycle and sudden stop history.

Despite the econometric challenges in characterizing data like those displayed in Figure 1, our estimated model fits Mexico's business cycles and sudden stop episodes well, and does not rely on large shocks to explain crises but instead lets the structure of the model explain those events. It produces business cycle statistics that match the second moments of the data and provides evidence on the relative importance of different shocks. Most importantly, our new specification of the collateral constraint 
Figure 1: Current Account and Output in Mexico, 1981-2016

(a) Current Account to Output Ratio

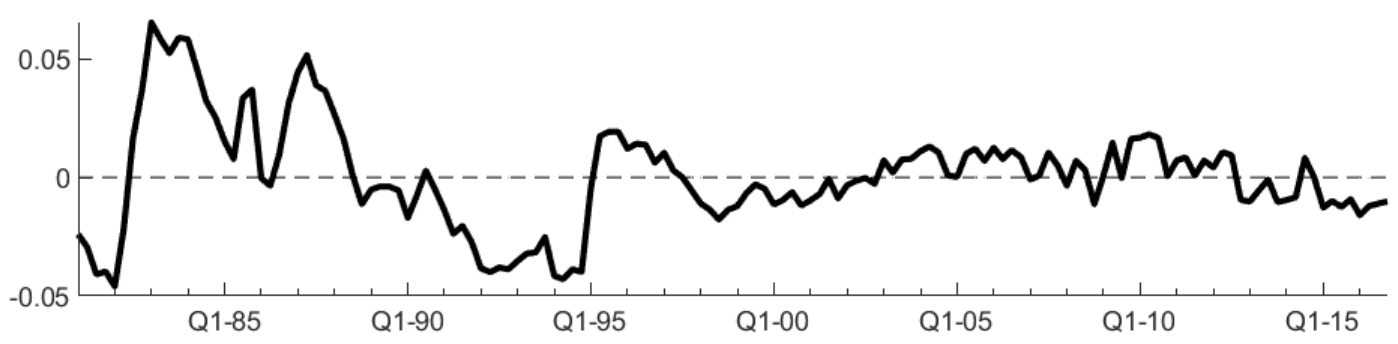

(b) Quarterly Output Growth Rate

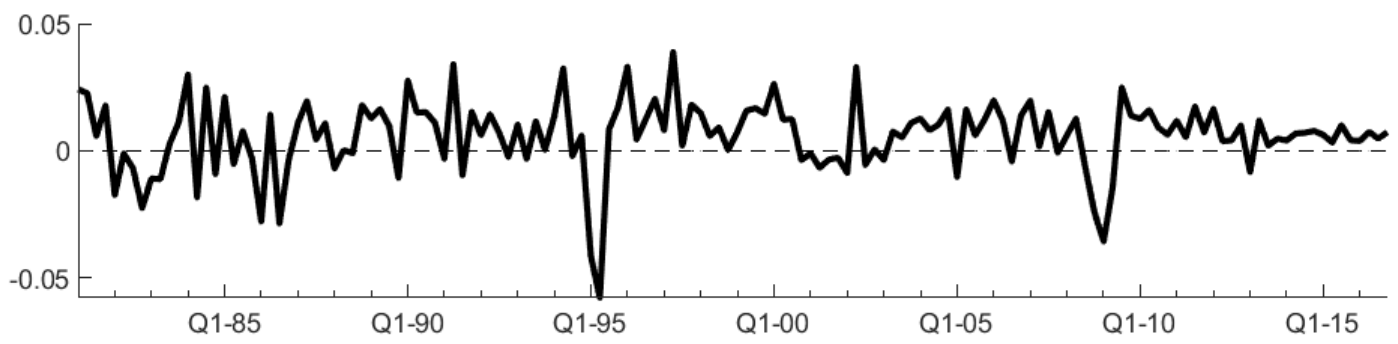

Note: Panel (a) plots Mexico's current account balance as a share of GDP. Panel (b) shows Mexico's quarterly log-change of real GDP. See the Appendix for data sources. Sample period 1981:Q1-2016:Q4.

identifies crisis episodes and dynamics of varying duration and intensity, consistent with evidence not only of large economic dislocation during financial crises but also sluggish build-up and recovery phases surrounding them (Cerra and Saxena, 2008; Reinhart and Rogoff, 2009; Boissay et al., 2016).

In particular, the estimated model identifies three financial crises: the Debt Crisis from 1981:Q3 to 1983:Q2, the Mexican peso crisis commonly referred to as the "Tequila crisis" from 1994:Q1 to 1996:Q1, and the spillover effect from the Global Financial Crisis from 2008:Q4 to 2009:Q3. The identified crisis episodes align well with a purely empirical notion of financial crisis in Mexico (Reinhart and Rogoff, 2009) and display duration about twice as long as the crisis peaks previously identified as sudden stops (Cerra and Saxena, 2008). The model-simulated dynamics of crisis episodes indicate that they are preceded by slowly unfolding booms and followed by economic stagnation, and are not only driven by a favorable external environment that suddenly reverses, but also domestic factors such as technology and demand shocks. We also show that different shocks matter more for different historical crisis 
episodes, as well as different phases of a given episode.

Related Literature A few papers have already estimated models with occasionally binding constraints. Bocola (2016), in particular, builds and estimates a model of occasionally occurring debt and banking crises. Notably, estimation is accomplished while solving the model with global methods, which avoids the use of approximations. However, this estimation is accomplished by first estimating the model outside the crisis, and then appending an estimate of the crisis in a second step. While this procedure does not matter for the specific application in Bocola (2016), it is not necessarily applicable more generally. Our approach permits joint estimation of the model inside and outside the crises and is potentially scalable to larger and more complex models, while maintaining a satisfactory level of accuracy relative to global solution methods.

Our paper relates also to Guerrieri and Iacoviello (2015), who develop OccBin, a set of procedures for the solution of models with occasionally binding constraints. OccBin is a certainty equivalent solution method that captures non-linearities but not precautionary effects, which are a critical feature of models with occasionally binding collateral constraints. ${ }^{1}$ A key feature of our approach is to preserve precautionary saving effects, as agents in the model adjust their behavior due to the presence of the constraint even when the constraint does not bind, and vice versa.

In the literature on Markov-switching DSGE models, our paper builds upon the method developed by Foerster et al. (2016), who developed perturbation methods for the solution of exogenous regime-switching models. The perturbation approach that we propose allows for second- and higher-order approximations that go beyond the linear models studied by Davig and Leeper (2007) and Farmer et al. (2011). In fact, we show that at least a second-order approximation is necessary in order to capture the effects of the endogenous switching.

The paper is also related to the literature that focuses on solving endogenous regime-switching models. Davig and Leeper (2008), Davig et al. (2010), and Alpanda and Ueberfeldt (2016) all consider endogenous regime-switching, but employ computationally costly global solution methods that hinder likelihood-based estimation. Lind (2014) develops a regime-switching perturbation approach for approximating

\footnotetext{
${ }^{1}$ Cuba-Borda et al. (2019) study how the solution method and likelihood misspecification interact and possibly compound each other.
} 
non-linear models, but it requires repeatedly refining the points of approximation and hence it is not suitable for estimation purposes. Maih (2015) and Barthlemy and Marx (2017) also propose perturbation methods for endogenous switching models, but employ a technique that approximates around regime-dependent steady states, which may not be a suitable choice given the relatively rare frequency of crises. In contrast, our perturbation method uses a single approximation point in the area of the state-space where the economy spends most of the time.

Importantly, we also contribute to the literature on likelihood-based estimation of Markov-switching DSGE models initiated by the seminal contributions of Bianchi (2013), and applied in Bianchi and Ilut (2017) and Bianchi et al. (2018). Our algorithm differs in two key respects. First, our regime-switching transition matrix reflects the endogenous nature of the switching. Second, conditional on the regime, we have a second order solution, so we employ the Sigma Point Filter to evaluate the likelihood function in place the modified Kalman filter in Bianchi (2013).

The specification of the constraint that we propose and the accompanying perturbation solution method could be easily applied to models with occasionally binding zero-lower bound on interest rates (for example, Adam and Billi, 2007; Aruoba et al., 2018; Atkinson et al., 2018). Existing methods for the estimation of such models may limit scalability due computational costs (Gust et al., 2017). Moreover, the occasionally binding zero lower bound is not comparable to the kind of constraints with endogenous collateral value that we estimate in this paper and is used in the normative literature on macroprudential policies (Benigno et al., 2013, 2016). Indeed, endogenous collateral valuation features different amplification mechanisms and entails additional computational complexities (Bianchi and Mendoza, 2018; Devereux et al., 2019).

The application of the methodology that we propose relates to the literature on emerging market business cycles, which includes Aguiar and Gopinath (2007), Mendoza (2010), Garcia-Cicco et al. (2010), Fernandez-Villaverde et al. (2011), and Fernandez and Gulan (2015), among others. Encompassing most shocks previously considered, we include in our analysis technology, preference, expenditure, interest rate, and terms of trade shocks. Relative to Mendoza (2010), we provide a Bayesian estimation of the model and consider a wider set of structural shocks, finding that some of the estimated values of the parameters that are not easily calibrated to the stylized facts of the data differ substantially. Relative to Garcia-Cicco et al. (2010), 
we evaluate empirically the relative importance of interest rate shocks in an fully non-linear framework, with a more articulated specification of the financial frictions driving amplification. Consistent with Fernandez and Gulan (2015) and Ates and Saffie (2016), we can fit ergodic second moments of the data well with uncorrelated shocks, but specific combinations of shocks are associated with crisis dynamics.

Finally, our paper relates to the now large literature on the Bayesian estimation of DSGE models (for example, Schorfheide, 2000; Otrok, 2001; Smets and Wouters, 2007; Liu et al., 2013). Our paper extends that successful approach to models with occasionally binding collateral constraints, which have become the benchmark for normative analysis of macro-prudential optimal policy (Bianchi and Mendoza, 2018; Benigno et al., 2013, 2016). Welfare-base analysis of optimal macroprudential policies with occasionally binding constraints depends critically on calibrations assumptions and collateral constraint formulations. Structural estimation of these parameters and likelihood based model validation can discipline model formulation, which in turn is critical for normative policy recommendations.

The rest of the paper is organized as follows. Section 2 describes the model and discusses the proposed formulation of the collateral constraint. Section 3 presents our perturbation solution method for endogenous regime-switching models. Section 4 describes the Bayesian estimation procedure. Section 5 reports the estimation results on parameters, model fit, and business cycle properties. Section 6 presents results on financial crises. Section 7 concludes. The Appendices include additional technical details and empirical results.

\section{The Model}

The model is a medium scale, workhorse framework for the analysis of business cycles and sudden stop crises in emerging market economies. The core of the model is as in Mendoza (2010), although we consider a larger set of shocks as in Garcia-Cicco et al. (2010). It features a small, open, production economy with an occasionally binding collateral constraint, that is subject to temporary productivity, intertemporal preference, expenditure, interest rate, and terms of trade shocks. ${ }^{2}$ The collateral

\footnotetext{
${ }^{2}$ We omit permanent technology shocks that could of the type analyzed by Aguiar and Gopinath (2007) because these long-run components cannot be estimated precisely over samples periods of length comparable to ours. Moreover, Garcia-Cicco et al. (2010) and Miyamoto and Nguyen (2017)
} 
constraint that we specify depends on the endogenous variables of the model, including borrowing, capital and its relative price, and hence leverage. Capital and debt choices respond to exogenous shocks, affecting borrowing, which in turn affects the probability of a binding collateral constraint.

Due to the occasionally binding nature of the constraint, this framework can account not only for normal business cycles, but also key aspects of financial crises in both emerging markets and advanced economies (Bianchi and Mendoza, 2018). While our application focuses on one particular type of crisis, the so called sudden stop in capital flows, our framework is generally applicable to other macroeconomic models with occasionally binding frictions and crises (for example, Kiyotaki and Moore, 1997; Iacoviello, 2005; Gertler and Karadi, 2011; Jermann and Quadrini, 2012; Liu et al., 2013; Gertler and Kiyotaki, 2015; Bocola, 2016; Schmitt-Grohe and Uribe, 2016; Boissay et al., 2016; Eichenbaum et al., 2020).

In the rest of this section, we discuss the representative household-firm and the borrowing constraint specification. The formal definition of the equilibrium and the full set of equilibrium conditions is reported in Appendix A.

\subsection{Preferences, Constraints, and Shock Processes}

There is a representative household-firm that maximizes the following utility function

$$
U \equiv \mathbb{E}_{0} \sum_{t=0}^{\infty}\left\{d_{t} \beta^{t} \frac{1}{1-\rho}\left(C_{t}-\frac{H_{t}^{\omega}}{\omega}\right)^{1-\rho}\right\},
$$

where $C_{t}$ denotes consumption, $H_{t}$ the supply of labor, and $d_{t}$ an exogenous and stochastic preference shock specified below. Households choose consumption, labor, capital $K_{t}$, imported intermediate inputs $V_{t}$ given an exogenous stochastic relative price $P_{t}$ also specified below, and holdings of real one-period international bonds, $B_{t}$. Negative values of $B_{t}$ indicate borrowing from abroad. The household-firm faces the budget constraint:

$$
C_{t}+I_{t}+E_{t}=Y_{t}-\phi r_{t}\left(W_{t} H_{t}+P_{t} V_{t}\right)-\frac{1}{\left(1+r_{t}\right)} B_{t}+B_{t-1},
$$

also find that the permanent technology shock is not quantitatively important in frameworks with financial frictions like ours in the case of Mexico. 
where $Y_{t}$ is gross domestic product and is given by

$$
Y_{t}=A_{t} K_{t-1}^{\eta} H_{t}^{\alpha} V_{t}^{1-\alpha-\eta}-P_{t} V_{t}
$$

Here, $A_{t}$ denotes the exogenous and stochastic level of technology. $E_{t}$ is an exogenous and stochastic expenditure process possibly interpreted as a fiscal or net export shock as in Garcia-Cicco et al. (2010). The term $\phi r_{t}\left(W_{t} H_{t}+P_{t} V_{t}\right)$ describes a working capital constraint, stating that a fraction of the wage and intermediate good bill must be paid in advance of production with borrowed funds. The relative price of labor and capital are given by $W_{t}$ and $q_{t}$, respectively, both of which are endogenous market prices, but taken as given by the individual household-firm. Gross investment, $I_{t}$, is subject to adjustment costs as a function of net investment:

$$
I_{t}=\delta K_{t-1}+\left(K_{t}-K_{t-1}\right)\left(1+\frac{\iota}{2}\left(\frac{K_{t}-K_{t-1}}{K_{t-1}}\right)\right) .
$$

Household-firms can borrow in international markets issuing one-period bonds that pay a market or country net interest rate $r_{t}$. The country interest rate between period $t$ and $t+1, r_{t}$, has three components: an exogenous persistent component, an exogenous transitory component, an endogenous component that depends on the level of debt. Thus, the country interest rate is given by

$$
r_{t}=r_{t}^{*}+\sigma_{r} \varepsilon_{r, t}+\psi_{r}\left(e^{\bar{B}-B_{t}}-1\right)
$$

where the persistent exogenous component, $r_{t}^{*}$, follows the process

$$
r_{t}^{*}=\left(1-\rho_{r^{*}}\right) \bar{r}^{*}+\rho_{r^{*}} r_{t-1}^{*}+\sigma_{r^{*}} \varepsilon_{r^{*}, t},
$$

with $\varepsilon_{r^{*}, t}$ and $\varepsilon_{r, t}$ i.i.d. $N(0,1)$ and $\sigma_{r^{*}}$ and $\sigma_{r}$ denoting parameters that control the variance of the two components. ${ }^{3}$

As Mendoza (2010) notes, in our model, the household-firm also faces a endogenous external financing premium on debt (EFPD), measured by the difference between the effective real interest rate, which corresponds to the intertemporal marginal rate

\footnotetext{
${ }^{3}$ While contemporaneous movements in $\varepsilon_{r^{*}, t}$ and $\varepsilon_{r, t}$ are not identified separately in equations (5) and (6), $\varepsilon_{r, t}$ will be identified in the data because of differences in persistence. Including both types of shocks helps fitting the observable counterpart variable in estimation.
} 
of substitution in consumption, $r_{t}^{h}=\mu_{t} / E_{t}\left[\mu_{t+1}\right]$, and the market interest rate, $r_{t}$. In fact, the Euler equation for $b_{t}, \mu_{t}=\lambda_{t}+\beta\left(1+r_{t}\right) \mathbb{E}_{t} \mu_{t+1}$, can be rearranged to show that EFPD $=\mathbb{E}_{t}\left[r_{t}^{h}-r_{t}\right]=\lambda_{t} / \beta E_{t}\left[\mu_{t+1}\right]$, where $\mu_{t}$ is the Lagrange multiplier on the budget constraint and $\lambda_{t}$ is the multiplier on the collateral constraint to be introduced shortly. Because of this feature, the endogenous interest rate component of $r_{t}$, $\psi_{r}\left(e^{\bar{B}-B_{t}}-1\right)$ in equation (5) will be calibrated to serve the sole purpose of inducing independence of the model steady state from initial conditions, as in Schmitt-Grohe and Uribe (2003), by setting $\psi_{r}$ to a very small value. ${ }^{4}$ In addition, we do not impose any correlation between the innovations to the interest rate process and the productivity process specified below.

The remaining exogenous processes for the preference shock $d_{t}$, the temporary technology shock $A_{t}$, the shock to the relative price of intermediate goods $P_{t}$, and the domestic expenditure shock $E_{t}$, are specified as follows:

$$
\begin{aligned}
\log d_{t} & =\rho_{d} \log d_{t-1}+\sigma_{d} \varepsilon_{d, t} \\
\log A_{t} & =\left(1-\rho_{A}\right) A^{*}+\rho_{A} \log A_{t-1}+\sigma_{A} \varepsilon_{A, t} \\
\log P_{t} & =\left(1-\rho_{P}\right) P^{*}+\rho_{P} \log P_{t-1}+\sigma_{P} \varepsilon_{P, t} \\
\log E_{t} & =\left(1-\rho_{E}\right) E^{*}+\rho_{E} \log E_{t-1}+\sigma_{E} \varepsilon_{E, t}
\end{aligned}
$$

where the starred variables and the $\rho$. coefficients denote the unconditional mean value and the persistence parameter of the processes, $\varepsilon_{., t}$ are assumed i.i.d. $N(0,1)$ innovations, and the $\sigma_{., t}$ parameters control the size of the process variances. ${ }^{5}$

\subsection{The Occasionally Binding Borrowing Constraint: An En- dogenous Regime-Switching Specification}

The central idea of this paper is to model the occasionally binding nature of a traditional inequality borrowing constraint as an endogenous regime-switching process.

\footnotetext{
${ }^{4}$ Mendoza (2010) uses an endogenous rate of time preference for this purpose.

${ }^{5}$ While possible in principle, we do not allow for regime-switching in the shocks processes, either in the intercepts or in the volatilities. This assumption is because we want the collateral constraint to drive regime-switching, rather than changes in the stochastic processes. Allowing for regime change in the shock processes might improve overall fit, but we want the economic features of the model and not changes in the exogenous shock processes to drive fluctuations and crisis episodes. Nonetheless, stochastic volatility may be an important feature of emerging markets (Fernandez-Villaverde et al., 2011; Arellano et al., 2019)
} 
In one regime, denoted $s_{t}=1$, the constraint binds strictly; in the second regime, denoted $s_{t}=0$ the constraint does not bind. In the binding regime, total borrowing equals a fraction $\kappa$ of the value of collateral $q_{t} K_{t}$ :

$$
\frac{1}{\left(1+r_{t}\right)} B_{t}-\phi\left(1+r_{t}\right)\left(W_{t} H_{t}+P_{t} V_{t}\right)=-\kappa q_{t} K_{t}
$$

Thus, in this regime total debt, which is borrowing for consumption smoothing plus working capital for the purchase of intermediate inputs and labor for production, is limited by the value of collateral. Limited working capital, as in Neumeyer and Perri (2005), Mendoza (2010), Fernandez and Gulan (2015), and Ates and Saffie (2016), amplifies the supply response of the economy to shocks in the constrained regime. In the unconstrained regime, lenders finance all desired borrowing, and the only constraint on borrowing is the natural debt limit. ${ }^{6}$

Given these two regimes representing the occasionally binding nature of the borrowing constraint, we assume a stochastic characterization of the transition between them, which eliminates the non-differentiability of the traditional inequality specification and has appealing empirical properties. The typical inequality specification of the borrowing constraint implies that, for given values of the endogenous and exogenous states, there is one specific level of leverage at which the constraint binds, and at that level of leverage the constraint always binds. In contrast, we assume that, for given values of the endogenous and exogenous states, there is a probability of switching to the constrained regime, but no specific level of leverage that triggers a switch to the constrained regime.

We assume that the probabilities of switching from one regime to the other depend on critical endogenous variables of the model. The probability of switching from the non-binding to the binding regime is a logistic function of the distance between actual borrowing and the borrowing limit equal to a fraction of the value of collateral. The probability of switching from the binding regime back to the nonbinding one is a logistic function of the collateral constraint multiplier. Therefore the transitions are affected by all endogenous variables in the model and agents have full information with rational expectations about these transitions probabilities.

This regime switching specification of the occasionally binding nature of the the

\footnotetext{
${ }^{6}$ An alternative interpretation for our setup is that $\kappa$ switches between a finite value in the binding regime that produces equation (11), and infinity in the non-binding regime.
} 
collateral constraint captures the salient macroeconomic empirical finding that the likelihood of a financial crisis increases with leverage, but high leverage does not necessarily lead to a financial crisis. For example, Jorda et al. (2013) proxy financial leverage by the rate of change of private bank credit relative to GDP. In their database of 14 advanced countries from 1870 to 2008 there are 35 recessions associated with financial crises. Across these episodes, the change in leverage before a crisis is highly heterogeneous, with the standard deviation of financial leverage twice the mean. This evidence suggests that the exact level of leverage at which a crisis occurs varies considerably across crisis episodes. ${ }^{7}$

In addition, a growing body of microeconomic evidence indicates that a deterministic specification of occasionally binding collateral constraints does not accurately capture lending and borrowing behaviors at the household and firm or bank level. For example, Chodorow-Reich and Falato (2017) and Greenwald (2019) among others, show that loan covenants are used to renegotiate credit lines as borrowers approach their limits, rather than simply being cut off from funding as soon as they face financial stress. Campello et al. (2010) provide survey information on the behavior of financially constrained firms, and Ivashina and Scharfstein (2010) examine loan level data, showing that firms drew down pre-existing credit lines in order to satisfy their liquidity needs. Bank lending standards fluctuating over the cycle could also be consistent with a stochastic specification of the collateral constraint. Thus, in practice, collateral constraints do not seem to bind at any particular leverage ratio. ${ }^{8}$

In the rest of this section, we discuss a modified slackness condition associated with our specification of the occasionally binding borrowing constraint and how it permits casting a occasionally binding constraint model in the form of an endogenous regime-switching framework. We then spell out the assumptions that we make to model the transition between regimes. We conclude the section with some remarks about the implications of our formulation for model dynamics.

\footnotetext{
${ }^{7}$ The notion of "debt intolerance" discussed by Reinhart and Rogoff (2009) and credit surface of Fostel and Geanakoplos (2015) also are consistent with our stochastic specification.

${ }^{8}$ Exploring whether the our specification of the borrowing constraint may result from the solution of a limited enforcement problem with renegotiation, hidden liquidity, or random monitoring shocks is beyond the scope of this paper.
} 


\subsubsection{The Regime-Switching Slackness Condition}

Denote the Lagrange multiplier associated with equation (11) as $\lambda_{t}$ and define the "borrowing cushion," $B_{t}^{*}$ as the distance of actual borrowing from the debt limit:

$$
B_{t}^{*}=\frac{1}{\left(1+r_{t}\right)} B_{t}-\phi\left(1+r_{t}\right)\left(W_{t} H_{t}+P_{t} V_{t}\right)+\kappa_{t} q_{t} K_{t}
$$

When the borrowing cushion is small, total borrowing is high relative to the value of collateral, meaning that the leverage ratio is high.

The critical step is to implement the slackness condition $B_{t}^{*} \lambda_{t}=0$ so that the two variables, $B_{t}^{*}$ and $\lambda_{t}$, are zero if the economy is in the relevant regime: $\lambda_{t}=$ 0 in the non-binding regime, and $B_{t}^{*}=0$ in the binding regime. To implement this restriction and be consistent with regime-switching DSGE models in which the parameters are the model objects that change state, we define two auxiliary regimedependent parameters, $\varphi\left(s_{t}\right)$ and $\nu\left(s_{t}\right)$, such that $\varphi(0)=\nu(0)=0$, and $\varphi(1)=$ $\nu(1)=1 .^{9}$ Next, we introduce the following regime-switching slackness condition:

$$
\varphi\left(s_{t}\right) B_{s s}^{*}+\nu\left(s_{t}\right)\left(B_{t}^{*}-B_{s s}^{*}\right)=\left(1-\varphi\left(s_{t}\right)\right) \lambda_{s s}+\left(1-\nu\left(s_{t}\right)\right)\left(\lambda_{t}-\lambda_{s s}\right)
$$

where $B_{s s}^{*}$ and $\lambda_{s s}$ are the steady state borrowing cushion and collateral constraint multiplier, respectively, defined more precisely in Section 3 below. It is now easy to see that equation (13) implies that, as desired, when $s_{t}=0$ then $\lambda_{t}=0$, and when $s_{t}=1$ then $B_{t}^{*}=0$. Thus, our formulation satisfies the slackness condition $B_{t}^{*} \lambda_{t}=0$ characterizing the representative household-firm's optimization problem. Yet, given a regime $s_{t}$, equation (13) remains continuously differentiable for any value of $B_{t}^{*}$ or $\lambda_{t}$, as no inequality constraint is imposed.

Technically, equation (13) "preserves" information in the perturbation approximation that we introduce in Section 3, since, at first order, both variables are constant in the respective regimes. The use of the regime-dependent switching parameters, $\varphi\left(s_{t}\right)$ and $\nu\left(s_{t}\right)$, follows from the Partition Principle of Foerster et al. (2016), which separates parameters based upon whether they affect the steady state or not. Intu-

\footnotetext{
${ }^{9}$ In our model these parameters coincide with the regime-switching indicator variable $s_{t}$, but in more general settings they may not. The notation provides a general formulation of the modified slackness condition that is applicable to other setups possibly different than the one associated with our specific application. See, for example, the discussion of our stochastic specification in the context of other model settings in Binning and Maih (2017).
} 
itively, $\varphi\left(s_{t}\right)$ captures the level of the economy changing across regimes (e.g., capital is lower when the constraint binds), while $\nu\left(s_{t}\right)$ captures the dynamic responses differing across regimes (e.g., the response of investment to shocks changes when the constraint binds).

\subsubsection{Modelling Endogenous Regime-Switching}

To model the transition from one regime to the other, we rely on logistic functions of endogenous variables determined in equilibrium. ${ }^{10}$ Specifically, we assume that the transition from the non-binding to the binding regime depends on the borrowing cushion, $B_{t}^{*}$ :

$$
\operatorname{Pr}\left(s_{t+1}=1 \mid s_{t}=0, B_{t}^{*}\right)=\frac{\exp \left(-\gamma_{0} B_{t}^{*}\right)}{1+\exp \left(-\gamma_{0} B_{t}^{*}\right)} .
$$

Thus, the likelihood that the constraint binds in the following period depends on the size of the borrowing cushion in the current period. The parameter $\gamma_{0}$ controls the steepness of the logistic function, determining the sensitivity of the probability of switching regime to the size of the borrowing cushion. When $\gamma_{0}$ is positive, as the cushion declines the probability of switching to the binding regime increases. Note here that, for certain draws from the logistic function, the borrowing cushion could be negative and the economy could temporarily remain in the non-binding regime.

Similarly, when the constraint binds, the transition probability to the non-binding regime is a logistic function of the Lagrange multiplier, $\lambda_{t}$, according to

$$
\operatorname{Pr}\left(s_{t+1}=0 \mid s_{t}=1, \lambda_{t}\right)=\frac{\exp \left(-\gamma_{1} \lambda_{t}\right)}{1+\exp \left(-\gamma_{1} \lambda_{t}\right)}
$$

The probability of switching back from the constrained to the unconstrained regime, therefore, depends on the shadow value of the economy's desired borrowing relative to the limit set by the collateral constraint. As in the case of a switch from the constrained to constrained regime, the parameter $\gamma_{1}$ affects the sensitivity of this probability to the value of the multiplier. For positive $\gamma_{1}$, a large positive multiplier implies that the constraint binds tightly, and the probability of exiting the binding regime is lower. As the multiplier declines, this probability increases. Again, as

\footnotetext{
${ }^{10}$ Logistic functions have the advantage that they are tractable and parsimoniously parameterized. Bocola (2016) and Kumhof et al. (2015) use a logistic function to model the transition to a default regime, and Davig et al. (2010) and Bi and Traum (2014) use it to study hitting a fiscal limit.
} 
before, in the binding regime, it is possible that the desired level of borrowing is less than the level forced upon it by the binding regime, which would manifest itself with a negative collateral constraint multiplier. ${ }^{11}$

Putting equations (14) and (15) together, the regime-switching model has an endogenous transition matrix

$$
\mathbb{P}_{t}=\left[\begin{array}{cc}
1-\frac{\exp \left(-\gamma_{0} B_{t}^{*}\right)}{1+\exp \left(-\gamma_{0} B_{t}^{*}\right)} & \frac{\exp \left(-\gamma_{0} B_{t}^{*}\right)}{1+\exp \left(-\gamma_{0} B_{t}^{*}\right)} \\
\frac{\exp \left(-\gamma_{1} \lambda_{t}\right)}{1+\exp \left(-\gamma_{1} \lambda_{t}\right)} & 1-\frac{\exp \left(-\gamma_{1} \lambda_{t}\right)}{1+\exp \left(-\gamma_{1} \lambda_{t}\right)}
\end{array}\right]
$$

\subsubsection{Remarks on the Endogenous Regime-Switching Formulation}

A few remarks are useful on how our stochastic formulation of the borrowing constraint works and differs relative to the typical inequality formulation.

First, the regime draw from the logistic functions in a given period is determined before exogenous shocks are realized and economic decisions are made during that period. Figure 2 summarizes the model timing and shows that, at the start of a given period $t$, the regime outcome $s_{t}$ is drawn from the logistic distributions as a function of previous period borrowing cushion and collateral constraint multiplier, $B_{t-1}^{*}$ and $\lambda_{t-1}$. Next, exogenous shocks, which are orthogonal to the realization of the regime, are realized, and agents take decisions during period $t$ based on the regime outcome, $s_{t}$, as well as a probability distribution over the next regime realization, $s_{t+1}$, as in equation (14) or (15). These decisions pin down all endogenous variables, including the borrowing cushion $B_{t}^{*}$ or the multiplier $\lambda_{t}$. Finally, the regime realization for period $t+1$ is drawn based on $B_{t}^{*}$ and $\lambda_{t}$, and so on.

Second, as we have already noted, an implication of our setup is that entry and exit of the economy from the binding regime occurs stochastically and hence may happen earlier or later than a deterministic formulation might imply. The fact that the borrowing cushion and multiplier can take negative values implies that the build up to, or duration of financial crises might persist. Likewise, the fact that a regimeswitch can occur despite positive values of the cushion and multiplier implies the entry into or exit from crises might occur relatively sooner than it might otherwise. As a result, the framework can potentially capture both rapid movements and slow

\footnotetext{
${ }^{11}$ By construction, the transition probabilities equal 0.5 when their arguments are zero. In principle, one could relax this assumption by introducing a constant into the arguments of equations (14-15). However, preliminary estimates that allowed for this degree of freedom indicated these additional parameters were effectively zero, so for simplicity we omit them from the beginning.
} 
Figure 2: Model Timing

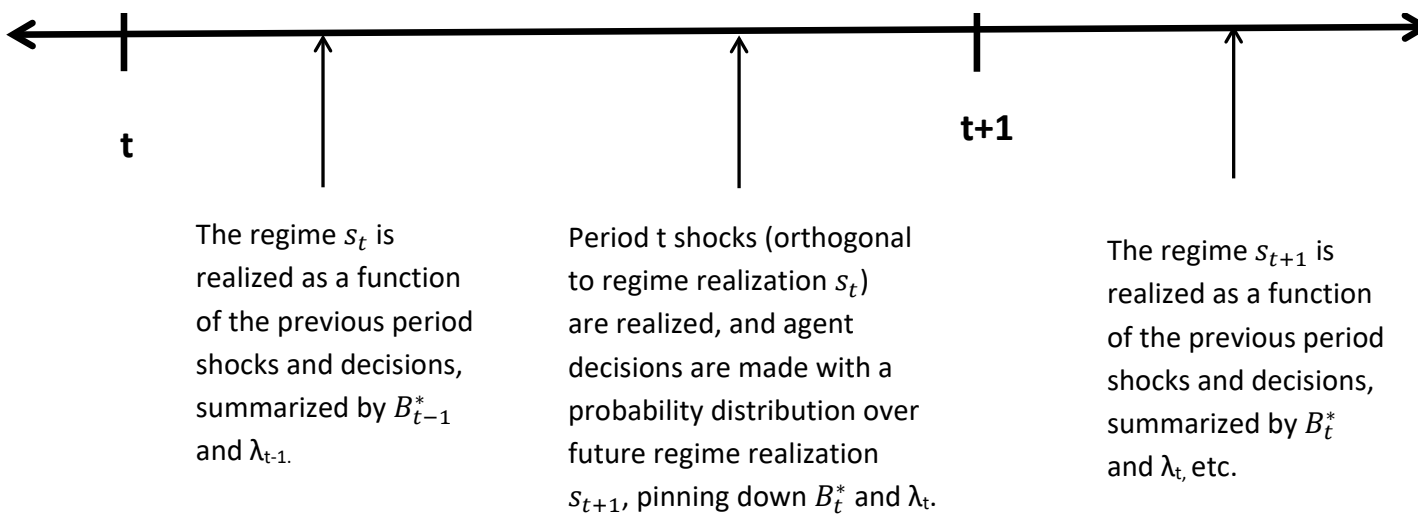

descents into crises and their recoveries. For instance, negative values of the borrowing cushion in the non-binding regime are possible if the probability of a binding regime is elevated but such outcome is not realized; such an outcome will tend to postpone crisis episodes. Conversely, in the non-binding regime, the logistic function can switch the economy into the binding regime in the following period even if the borrowing cushion in the current period is still positive; such an outcome accelerates the occurrence of crises. How likely these outcomes are depend on the parameter of the relevant logistic function, $\gamma_{0}$. The same logic applies to a probabilistic exit from the binding regime that depends on the multiplier $\lambda_{t}$ and the parameter $\gamma_{1}$. The economy might be stuck in the constrained regime past the time when the collateral constrained multiplier turned negative, extending the duration of the crisis. In fact, in this case, the economy may be "forced" to borrow the amount set by the constraint, which might be more than desired, until a non-binding realization of the regime is drawn. Conversely, despite positive values of the multiplier, the economy may end up coming out of the binding regime early.

The third implication of our setup is that, as the the transition probability are endogenous, they are time-varying. In contrast, the exogenous Markov-switching setup (Davig and Leeper, 2007; Farmer et al., 2011; Bianchi, 2013; Foerster et al., 2016) has a constant probability of transitioning between regimes that is independent of the structural shock realizations and the agent decisions. For this reason, our endogenous-switching framework is capable of generating long- or short-lived-bindingregime episodes depending on the realization of shocks and agents' decisions.

Last but not least, in our set up, agents in the non-binding regime know that 
higher leverage increases the probability of switching to the binding regime, and viceversa. This knowledge preserves the interaction in agents' behavior between the two regimes and gives rise to precautionary behavior, distinguishing this class of models from those in which financial frictions are always binding or are approximated with solution methods that eliminate the interactions across regimes.

\section{Solving the Endogenous Switching Model}

This Section describes our solution method for endogenous regime-switching models. The model proposed in the previous section can in principle be solved using global methods, as for example in Davig et al. (2010). In the case of our application, with two endogenous and five exogenous state variables, the regime indicator, plus six exogenous shocks, using a global solution method would be extremely time consuming, and it would quickly become prohibitive with larger modes, precluding likelihoodbased estimation. Instead, we solve the model using a perturbation approach, which allows for an accurate approximation that is fast enough to permit estimation and potentially applicable to larger frameworks beyond our medium-scale model. We now describe the approximation point and how to define a steady state in this setup, the Taylor-series expansions, and discuss the importance of approximating at least to a second-order in our framework. The competitive equilibrium of the endogenous regime-switching model is defined formally in Appendix A. The derivations of the Taylor-series expansions and other details of the solution method are reported in Appendix B.

\subsection{Defining the Steady State}

Given the regime-switching slackness condition (13), defining a non-stochastic steady state of an endogenous regime-switching model is challenging. A steady state in this setting can be defined as a state in which all shocks have ceased and the regimeswitching variables that affect the level of the economy $\left(\varphi\left(s_{t}\right)\right)$ take the ergodic mean associated with the steady state transition matrix:

$$
\mathbb{P}_{s s}=\left[\begin{array}{cc}
1-\frac{\exp \left(-\gamma_{0} B_{s s}^{*}\right)}{1+\exp \left(-\gamma_{0} B_{s s}^{*}\right)} & \frac{\exp \left(-\gamma_{0} B_{s s}^{*}\right)}{1+\exp \left(-\gamma_{0} B_{s s}^{*}\right)} \\
\frac{\exp \left(-\gamma_{1} \lambda_{s s}\right)}{1+\exp \left(-\gamma_{1} \lambda_{s s}\right)} & 1-\frac{\exp \left(-\gamma_{1} \lambda_{s s}\right)}{1+\exp \left(-\gamma_{1} \lambda_{s s}\right)}
\end{array}\right]
$$


Since this matrix depends on the steady state level of the borrowing cushion and the multiplier, $B_{s s}^{*}$ and $\lambda_{s s}$, which in turn depend upon the ergodic mean of the regimeswitching parameter $\varphi\left(s_{t}\right)$, such a steady state is the solution of a fixed point problem that is described in more detail in Appendix B.

More specifically, consider the model regime-specific parameters defined above and distinguish between $\varphi\left(s_{t}\right)$, which affect the level behavior of the economy, and $\nu\left(s_{t}\right)$, which affect only its dynamics with no effects on the steady state. Then denote with $\xi=\left[\xi_{0}, \xi_{1}\right]$ the ergodic vector of $\mathbb{P}_{s s}$. Next, apply the Partition Principle of Foerster et al. (2016), to focus only on parameters that affect the level of the economy, and write their ergodic mean of $\varphi\left(s_{t}\right)$, denoted $\bar{\varphi}$, as

$$
\bar{\varphi}=\xi_{0} \varphi(0)+\xi_{1} \varphi(1)
$$

Defining the steady state as the state in which the auxiliary parameter $\varphi\left(s_{t}\right)$ is at its ergodic mean value $\bar{\varphi}$ implies that the approximation point constructed is a weighted average of the steady states of two separate models: a model in which only the non-binding regime occurs, and one in which only the binding regime occurs. How close our approximation point is to each of these two other steady states, therefore, depends on the frequency of being in each of the two regimes. As in our application episodes of binding regime have limited duration, the ergodic mean is a natural candidate as perturbation point. Given the nature of our application with slow-moving capital and debt state variables, this perturbation point will be in the area of the state space in which the economy operates most frequently. In fact, since the binding regime tends to be self-limiting-that is, being in the binding regime causes the economy to reduce leverage and hence switch back to the non-binding regime-the economy will rarely reach the area around the steady state of the "binding regime only." 12

\footnotetext{
${ }^{12}$ Alternative methods for finding solutions to endogenous regime-switching models, such as Maih (2015) and Barthlemy and Marx (2017), propose using regime-dependent steady states as multiple approximation points. Such a strategy would not be suitable for our purposes because the binding regime steady state is a poor approximation point given that the regime is infrequent and usually of shorter duration than normal cycles of expansions and contractions.
} 


\subsection{The Solution and Its Properties}

Equipped with the steady state of the endogenous regime-switching economy, we construct a second-order approximation to the policy functions by taking derivatives of the equilibrium conditions. We relegate details of these derivations to the Appendix $\mathrm{B}$, but here we provide a summary.

For each regime $s_{t}$, the policy functions of our model take the form

$$
\mathbf{x}_{t}=h_{s_{t}}\left(\mathbf{x}_{t-1}, \varepsilon_{t}, \chi\right), \quad \mathbf{y}_{t}=g_{s_{t}}\left(\mathbf{x}_{t-1}, \varepsilon_{t}, \chi\right),
$$

where $\mathbf{x}_{t}$ denotes predetermined variables, $\mathbf{y}_{t}$ non-predetermined variables, $\varepsilon_{\mathbf{t}}$ the set of shocks, and $\chi$ a perturbation parameter such that when $\chi=1$ the fully stochastic model results and when $\chi=0$ the model reduces to the non-stochastic steady state defined above. Using these functional forms, we can express the equilibrium conditions conditional on regime $s_{t}$ as

$$
\mathbb{F}_{s t}\left(\mathbf{x}_{t-1}, \varepsilon_{t}, \chi\right)=0 \text {. }
$$

We then stack the regime-dependent conditions for $s_{t}=0$ and $s_{t}=1$, denoting the resulting system of equations with $\mathbb{F}\left(\mathbf{x}_{t-1}, \varepsilon_{t}, \chi\right)$, and successively differentiate with respect to $\left(\mathbf{x}_{t-1}, \varepsilon_{t}, \chi\right)$, evaluating them at the steady state. The systems

$$
\mathbb{F}_{\mathbf{x}}\left(\mathbf{x}_{s s}, \mathbf{0}, 0\right)=0, \quad \mathbb{F}_{\varepsilon}\left(\mathbf{x}_{s s}, \mathbf{0}, 0\right)=0, \quad \mathbb{F}_{\chi}\left(\mathbf{x}_{s s}, \mathbf{0}, 0\right)=0
$$

can then be solved for the unknown coefficients of the first-order Taylor expansion of the policy functions in equation (19).

A second-order approximation can be found by taking the second derivatives of $\mathbb{F}\left(\mathbf{x}_{t-1}, \varepsilon_{t}, \chi\right)$. In the end, we have matrices $H_{s t}^{(1)}$ and $G_{s_{t}}^{(1)}$ characterizing the first-order coefficients, and $H_{s_{t}}^{(2)}$ and $G_{s_{t}}^{(2)}$ characterizing the second-order coefficients. Therefore, the approximated policy functions are

$$
\begin{gathered}
\mathbf{x}_{t} \approx \mathbf{x}_{s s}+H_{s t}^{(1)} S_{t}+\frac{1}{2} H_{s t}^{(2)}\left(S_{t} \otimes S_{t}\right) \\
\mathbf{y}_{t} \approx \mathbf{y}_{s s}+G_{s t}^{(1)} S_{t}+\frac{1}{2} G_{s t}^{(2)}\left(S_{t} \otimes S_{t}\right)
\end{gathered}
$$

where $S_{t}=\left[\begin{array}{lll}\left(\mathbf{x}_{t-1}-\mathbf{x}_{s s}\right)^{\prime} & \varepsilon_{t}^{\prime} & 1\end{array}\right]^{\prime}$. 
Our perturbation method produces a single approximated set of policy functions, but cannot be used to guarantee that the solution is unique. This limitation is common to models of occasionally binding constraints that are solved globally with converging numerical algorithms without guaranteeing uniqueness. With endogenous regime-switching, we also lack conditions for ensuring stability of the full solution; instead, we check the mean-squared stability of the first-order approximation paired with the steady state transition matrix $\mathbb{P}_{s s}$ (Farmer et al., 2011; Foerster et al., 2016), and additionally check for explosive simulations.

Our solution method is fast, and can readily be scaled to handle larger models. In all, we have 23 equations that characterize the equilibrium, two endogenous and five exogenous state variables, one regime indicator, and six shocks. Our computational approach is similar to that in Fernandez-Villaverde et al. (2015): we use Mathematica to take symbolic derivatives and export these derivatives so that we can use Matlab to solve the model repeatedly for different parameterizations. The model solves in about a second on a standard laptop. ${ }^{13}$

The proposed solution method is also accurate. We tested for accuracy of the proposed solution method applied to our model, as well as in the smaller model of Jermann and Quadrini (2012) in which we can more easily compare our perturbation method to with global solution methods. We find Euler equation errors for the model we use in this paper on the order of $\$ 1$ per $\$ 1,000$ of consumption, a figure in line with the accuracy of perturbation methods applied to exogenous regime-switching models (Foerster et al., 2016) and standard models without regime-switching (Aruoba et al., 2006). When we compare the perturbation method we propose with a standard global method applied to the endogenous regime-switching version of the model in Jermann and Quadrini (2012), or the same model with the inequality constraint, we find that our solution methods produce similar second moments and model dynamics for key variables of interest. Moreover, the global and perturbation solutions of the endogenous regime-switching version of this model produce very similar Euler equation errors-see Appendix C for more details.

\footnotetext{
${ }^{13} \mathrm{~A}$ core code that demonstrates the solution algorithm is available on request from the authors.
} 


\subsection{Approximation Order, Endogenous Switching and Pre- cautionary Saving}

Our endogenous regime-switching framework must be solved at least to the second order to capture the effects of endogenous probabilities on the policy rules, which include state-varying precautionary effects. If we were to use only a first-order approximation, our estimation would not capture precautionary behavior associated with rational expectations about the dependency of the probability of a regime change on the borrowing cushion and the multiplier. The following Proposition states this result formally.

Proposition 1 (Irrelevance of Endogenous Switching in a First-Order Approximation). The first-order solution to the endogenous regime-switching model is identical to the first-order solution to an exogenous regime-switching model in which the transition probabilities are given by the steady-state value of the time-varying transition matrix.

Proof. See Appendix C.

The Proposition illustrates that using a second-order approximation to the solution is necessary to characterize the model properties associated with the endogenous nature of the regime-switching, including particularly precautionary behavior. This result is similar to the one stating that, in models with only one regime, first-order solutions are invariant to the size of shocks, second-order solutions captures precautionary behavior, and third-order solutions are needed to capture the effects of stochastic volatility (Fernandez-Villaverde et al., 2015).

Unfortunately, the need to use a second-order approximation along with regimeswitching creates additional challenges for estimation purposes. We now turn to our strategy to address them.

\section{Estimating the Endogenous Switching Model}

We estimate the model with a full information Bayesian procedure. The posterior distribution has no analytical solution and we use Markov-Chain Monte Carlo (MCMC) methods to sample from it. Since the Metroplis-Hastings algorithm that we use for sampling is a standard tool used in the literature, we omit a discussion of this step in 
our procedure. The details of the construction of the state space representation and the filtering steps for the evaluation of the likelihood are reported in Appendix D.

A key obstacle in sampling from the posterior is the evaluation of the likelihood function. We face three difficulties here relative to linear DSGE models. The first is the non-linearity due to the presence of multiple regimes. The second is the need to approximate to the second-order the model solution that governs the decision rules in each regime. The third is the fact that the transition probabilities are endogenous. Bianchi (2013) develops an algorithm to address the first difficulty. Here we must use an alternative filter to deal with the second order solution and endogenous probabilities in a tractable manner. We use the Unscented Kalman Filter (UKF) to compute approximations to the evaluation of the likelihood function using Sigma Points. An alternative would be to use the Particle Filter (Fernandez-Villaverde and Rubio-Ramirez, 2007). However, the Particle Filter is not well-suited to our application, because the regime switching can lead to discarding a large number of simulated particles, lowering accuracy for a given number of particles and greatly increasing the computational cost of obtaining a given level of accuracy. Further, even with a deterministic filter, the filtering step in estimation is relatively costly at about 10 seconds per likelihood evaluation using Matlab; incorporating the Particle Filter would increase computing time significantly. ${ }^{14}$

The model's posterior distribution is highly non-linear, with many local modes due to the complexity of the model. To deal with this issue, we took the following steps: first, we estimated a version of the model without working capital and the occasionally binding constraint, this step yield an initial estimate of the exogenous processes and the non-financial parameters; second, conditional on these initial estimates, we performed a grid search over the remaining parameters $\left(\kappa, \phi, \gamma_{0}\right.$, and $\left.\gamma_{1}\right)$ to find high posterior regions; third, from the high posterior regions of the grid search, we used a mode-finding routine to identify the posterior mode, which forms the basis for our empirical results; lastly, we sampled 500,000 times from the posterior with a random-walk Metropolis-Hastings algorithm to explore the parameter space around the mode and characterize credible sets for the parameter estimates. ${ }^{15}$

\footnotetext{
${ }^{14}$ See Binning and Maih (2015) for a comparison between the Sigma Point filter and the Particle Filter in a regime-switching context, which includes degeneracy issues.

${ }^{15}$ For the last MCMC step, we adjusted the scale of the proposal density until we achieved an acceptance rate of 0.25 . The entire MCMC algorithm takes 58 days to complete.
} 


\subsection{Observables, Data, and Measurement Errors}

The model is estimated with quarterly data for GDP growth (gross output less intermediate input payments), consumption growth, investment growth, and intermediate import price growth, as well as the current account-to-output ratio, and a measure of the country real interest rate. GDP, consumption, and investment are in quarterly, demeaned log differences. ${ }^{16}$

As there are six shocks with six observables, we do not need measurement errors. However, measurement errors in the observation equation improves performance of the non-linear filter and accounts for any actual measurement error in the data. To limit their impact on the inference, we limit their variance to $5 \%$ of the variance of the observable variables. This means that our model will fit the data relatively closely on average; thus, how it performs across cycles and crises and whether it relies on large shocks to fit the data will be important in assessing model performance.

\subsection{Calibrated Parameters and Prior Distributions}

Our objective is to estimate critical parameters governing the model's dynamics in both the binding and non-binding regime, as well as the parameters that govern the transitions between regimes on which we do not have any prior information. To make inference on the parameters of interest while using relatively diffuse priors, we calibrate a subset of parameters on which we have reliable prior information. We now discuss our calibrated parameters, and then our use of priors in estimation.

Table 1 lists the parameters that we calibrate. ${ }^{17}$ We set these parameters largely following Mendoza (2010), who calibrated them based upon stylized facts from Mexico's National Accounts, but adapted to our model specification. One parameter that does not come from Mendoza (2010) is $\beta$, which we set to match the capital-to-output ratio. Another important parameter that we calibrate is $\psi_{r}$, which is estimated in Garcia-Cicco et al. (2010). We set it to a very small value for the sole purpose of eliminating the dependency of the steady state on initial conditions, while not allowing the parameter to affect the model dynamics (see Schmitt-Grohe and Uribe, 2003). ${ }^{18}$

\footnotetext{
${ }^{16}$ See Appendix $\mathrm{F}$ for details on variable definitions and data sources. The country interest rate is constructed, following Uribe and Yue (2006), and it is the US 3-Month Treasury Bill minus ex post US CPI inflation rate plus Mexico's EMBI Spread.

${ }^{17}$ See Appendix $\mathrm{E}$ for more details on the calibration and the targeted data moments.

${ }^{18}$ Even though we have a borrowing constraint and precautionary savings, the presence of $\psi_{r}>$
} 


\section{Table 1: Calibrated Parameters}

\begin{tabular}{c|c|c}
\hline \hline Parameter & Description & Value \\
\hline$\beta$ & Discount Factor & 0.9798 \\
$\rho$ & Risk Aversion & 2.0000 \\
$\omega$ & Labor Supply & 1.8460 \\
$\eta$ & Capital Share & 0.3053 \\
$\alpha$ & Labor Share & 0.5927 \\
$\delta$ & Depreciation Rate & 0.0228 \\
$P^{*}$ & Mean Import Price & 1.0280 \\
$E^{*}$ & Mean Expenditure & 0.2002 \\
$\psi_{r}$ & Interest Rate Debt Elasticity & 0.0010 \\
$\bar{B}$ & Neutral Debt Level & -6.1170 \\
\hline \hline
\end{tabular}

Setting $\psi_{r}$ to a very small value allows us to evaluate the model's ability to match the behavior of the trade balance and the other key stylized facts of the data without introducing an additional financial friction, in the form of a quantitatively important endogenous component of the market interest rate in equations (5)-(6).

Table 2 below summarizes our assumptions on the prior distributions. We set two types of priors on the parameters to be estimated. The first type is priors directly on the parameters. They impose sign restrictions and put lower prior probability on parameter values that generate implausible moments in model simulations. The second type of prior is on a model-implied object: the steady state transition probability of switching from the binding to to the non-binding regime, given by the steady state value of equation (14), $\operatorname{Pr}\left(s_{t+1}=1 \mid s_{t}=0, B_{s s}^{*}\right)$. We set this prior to be a Beta distribution with mean 0.25 and variance of 0.25 . This prior puts lower probability mass on combinations of parameters that either generate extremely infrequent transitions to the binding regime, or that imply the economy exits the binding regime almost immediately. ${ }^{19}$

0 serves the same purpose as endogenous discounting in Mendoza (2010). Recall here that our perturbation solution is constructed around a point between the steady state of the "non-binding regime", which depends on $\psi_{r}$, and the "binding regime".

${ }^{19}$ Priors on model-implied objects have been used by, for example, Otrok (2001) and Del Negro and Schorfheide (2008). 


\section{Table 2: Estimated Parameters}

\begin{tabular}{|c|c|c|c|c|c|c|}
\hline \multirow[t]{2}{*}{ Par. } & \multirow[t]{2}{*}{ Description } & \multirow[t]{2}{*}{ Prior } & \multicolumn{4}{|c|}{ Posterior } \\
\hline & & & Mode & $5 \%$ & $50 \%$ & $95 \%$ \\
\hline$\iota$ & Capital Adj. & $\mathrm{N}(10,5)$ & 12.703 & 12.649 & 12.701 & 12.724 \\
\hline$\phi$ & Working Cap. & $\mathrm{U}(0,1)$ & 0.7113 & 0.7102 & 0.7153 & 0.7207 \\
\hline$r^{*}$ & Mean Int. Rate & $\mathrm{N}(0.0177,0.01)$ & 0.0172 & 0.0115 & 0.0165 & 0.0216 \\
\hline$\kappa$ & Leverage & $\mathrm{U}(0,1)$ & 0.1727 & 0.1592 & 0.1756 & 0.1989 \\
\hline$\rho_{a}$ & Autocor. TFP & $\mathrm{B}(0.6,0.2)$ & 0.9796 & 0.9653 & 0.9793 & 0.9881 \\
\hline$\rho_{e}$ & Autocor. Exp & $\mathrm{B}(0.6,0.2)$ & 0.9111 & 0.9066 & 0.9132 & 0.9237 \\
\hline$\rho_{p}$ & Autocor. Imp Price & $\mathrm{B}(0.6,0.2)$ & 0.9711 & 0.9609 & 0.9754 & 0.9549 \\
\hline$\rho_{d}$ & Autocor. Pref. & $\mathrm{B}(0.6,0.2)$ & 0.9810 & 0.9753 & 0.9810 & 0.9843 \\
\hline$\rho_{r^{*}}$ & Autocor. Persist. Int. Rate & $\mathrm{B}(0.6,0.2)$ & 0.8929 & 0.8782 & 0.8896 & 0.8995 \\
\hline$\sigma_{a}$ & SD TFP & $\mathrm{IG}(0.01,0.01)$ & 0.0083 & 0.0066 & 0.0081 & 0.0098 \\
\hline$\sigma_{e}$ & SD Exp. & $\mathrm{IG}(0.1,0.1)$ & 0.1806 & 0.1672 & 0.1816 & 0.1892 \\
\hline$\sigma_{p}$ & SD Imp. Price & $\mathrm{IG}(0.1,0.1)$ & 0.0471 & 0.0382 & 0.0452 & 0.0524 \\
\hline$\sigma_{d}$ & SD Pref. & $\mathrm{IG}(0.1,0.1)$ & 0.1123 & 0.0998 & 0.1123 & 0.1194 \\
\hline$\sigma_{r}$ & SD Trans. Int. Rate & $\mathrm{IG}(0.01,0.01)$ & 0.0028 & 0.0013 & 0.0025 & 0.0044 \\
\hline$\sigma_{r^{*}}$ & SD, Persist Int. Rate & $\mathrm{IG}(0.01,0.01)$ & 0.0047 & 0.0037 & 0.0047 & 0.0059 \\
\hline$\gamma_{0}$ & Logistic, Enter Binding & $\mathrm{U}(0,150)$ & 13.552 & 10.903 & 13.712 & 18.014 \\
\hline$\gamma_{1}$ & Logistic, Exit Binding & $\mathrm{U}(0,150)$ & 17.798 & 15.784 & 17.800 & 19.806 \\
\hline
\end{tabular}

Notes: Estimated parameters, with prior distribution and posterior moments. Priors are Normal, Uniform, Beta, or Inverse Gamma; prior distributions show mean and variance, except for uniform where lower and upper bounds are shown. Posterior distribution shows mode, along with 5 -th, 50-th, and 95-th percentiles from MCMC posterior draws.

\section{Empirical Results}

Our empirical findings comprise four sets of results. First, we present the estimated parameters, which helps us to characterize the tightness of the working capital and borrowing constraints, and the endogenous transition probabilities. Second, we examine the estimated model's fit to the data. Third, we examine the model's performance from a business cycle perspective, comparing moments in the model and the data and assessing the relative importance of different shocks for regular business cycles. Our fourth set of results focuses on financial crises. We report and discuss the first three sets of results in this section, and present the fourth set in Section 6 . 


\subsection{Estimated Parameters}

For our first set of results focuses on the estimated parameters. Table 2 reports the mode, the median, the 5th, and the 95th percentile of the posterior distribution of the estimated parameters. The estimated mean interest rate, slightly below $1.75 \%$ per quarter, is close to the value estimated by Mendoza (2010). Note that the posterior coverage interval for this variable is fairly diffuse, indicating some uncertainty in its true value. The remaining parameters have tightly estimated posteriors, so we will focus the discussion on posterior modes for the remaining parameters.

Importantly, the model provides precise estimates of critical parameters, namely the investment adjustment cost, working capital, and leverage parameters, and the parameters of the logistic function that help match the time series of the observable variables during both business cycles and financial crises. These parameters cannot be easily measured directly from stylized facts of the data-unlike, for example, capital or labor shares-but are nonetheless important for explaining the behavior of the economy and the amplification of shocks.

The estimate of the investment adjustment cost parameter, $\iota$, which controls investment volatility, is 12.7. This parameter is model dependent and has no real interpretation outside of a particular model; for example, considering an annual frequency, Mendoza (2010) calibrated this parameter to 2.75. The estimate for the working capital constraint parameter indicates that $71 \%$ of the wage and intermediate good bill needs to be paid in advance with borrowed funds; this estimate is substantially higher than the $25.79 \%$ value set by Mendoza (2010), but much lower than the $100 \%$ used by Neumeyer and Perri (2005) or the $125 \%$ used by Uribe and Yue (2006). The estimate is close to the 60\% calculated by Ates and Saffie (2016), who use interest payments and production costs from Chilean microeconomic data. The estimated value of the leverage parameter in the borrowing constraint $(\kappa)$ is 0.17 , indicating less than a fifth of the value of capital serves as collateral. The estimate is slightly tighter than the benchmark value of 0.20 chosen by Mendoza (2010), which is is right inside the confidence set, and on the low end of the 0.15 to 0.30 range of alternative values considered in that calibration.

The posterior modes of the logistic parameters in equations (14) and (15) are 13.6 and 17.8, respectively, estimated in a tight range relative to the very loose prior. These estimates are significantly different from zero, thus suggesting that the data 


\section{Figure 3: Logistic Functions and Distributions of Their Arguments}

(a) Borrowing Cushion and Transition Probability in Non-Binding Regime

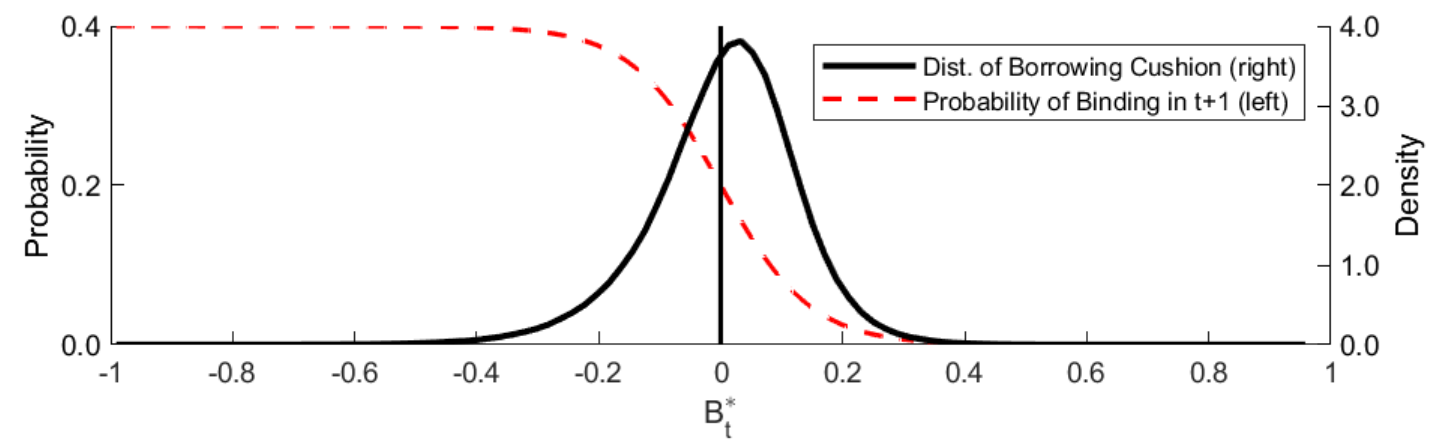

(b) Multiplier and Transition Probability in Binding Regime

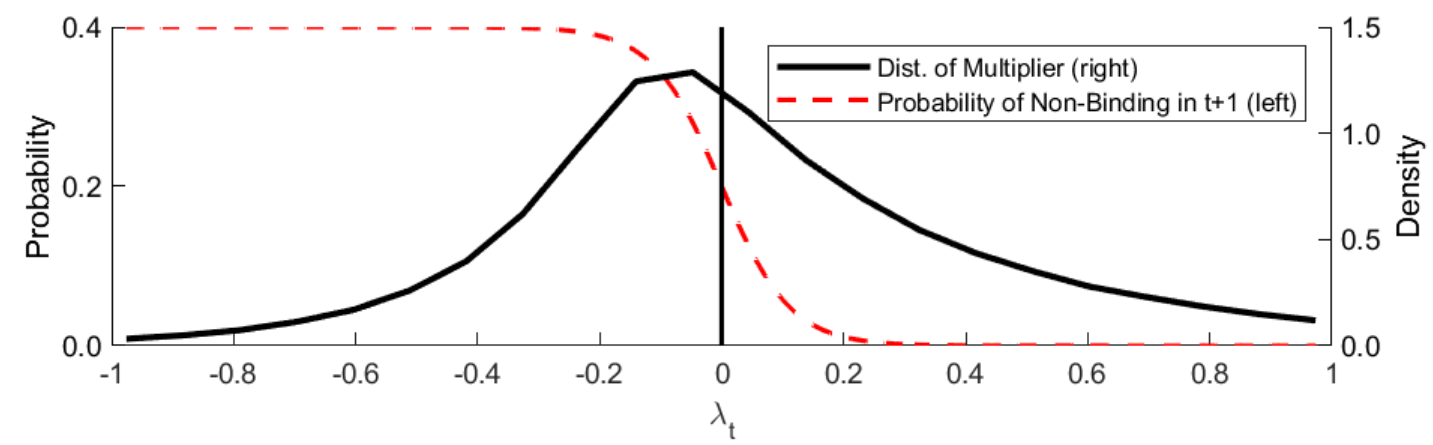

Note: The top panel shows the model-implied distribution of the borrowing cushion $B^{*}$ in the non-binding regime, and the logistic transition function to the binding regime as in equation (14) implied by our estimates. The bottom panel shows the model-implied distribution of the multiplier $\lambda$ in the binding regime, and the transition function to the non-binding regime as in equation (15) implied by our estimates.

reject a model specification in which the transition probabilities are exogenous, which is in principle allowed for under the prior distribution.

Figure 3 plots the implied probabilities from equation (14) and (15), evaluated at the posterior mode value of $\gamma_{0}$ and $\gamma_{1}$, together with the estimated ergodic distributions of their arguments, the borrowing cushion, $B^{*}$ and the the constraint multiplier, $\lambda$. The figure shows that the ergodic distribution of the borrowing cushion is centered on a positive value, as the economy spends most of its time in the non-binding regime, above the borrowing limit. As the borrowing cushion falls, the probability of switching to the binding regime increases, and gradually reaches 1 for small negative values, with very little probability mass on large negative realizations of the borrowing cushion. 
On the other hand, once the economy is in the binding regime, the ergodic distribution of the multiplier is centered on small negative values, with more probability mass on the right tail than the left tail. As $\lambda$ approaches 0 , the probability of switching to the non-binding regime increases and quickly reaches 1 , with a mode on a small negative value. Nonetheless, the there is a significant probability mass for larger negative values. As we explained earlier, negative values of $\lambda$ reflect instances in which, had the economy been in the non-binding regime, the borrowing cushion would be positive (as a result of the shock realizations and agent decisions as illustrated in Figure 2), but a switch to the non-binding regime at has not been drawn yet. ${ }^{20}$

\subsection{Model Fit}

Our second set of results provides evidence on how the estimated model fits the observable variables. The model fit is summarized by Figure 4, which plots observable variables used in the estimation together with the fitted values. The Figure also includes the peaks of the model-identifed crises (red bars), which we define and discuss in more detail in Section 6 and are the trough quarters of the model-identified crisis episodes. The fitted series tracks the actual data very closely. Importantly, the model estimates track the data consistently throughout the sample, during both regular business cycle and crisis periods. For example, around the 1995 "Tequila Crisis," the data show large drops and rebounds in output, consumption, and investment growth, and a very sharp reversal in the current account to output ratio. If, by contrast, one were to observe a loss of fit during crisis episodes, it would suggest that our estimated model finds it difficult to match the data dynamics during these episodes of critical interest in the empirical analysis. As additional results reported in Appendix $G$ on the estimated structural shocks illustrate, the estimated model fits the data without relying on large shocks. Instead, it explains crisis dynamics using the model's internal propagation mechanisms that amplify the effects of usual sized shocks.

\footnotetext{
${ }^{20}$ Sufficiently negative values of $\lambda$, approximately below -0.2 , produce a nearly deterministic switch back to the binding regime. The ergodic distribution of $\lambda$ in the binding regime (Figure $3 \mathrm{~b}$ ) implies that the probability of exiting that regime exceeds $99 \%$ about $1 / 4$-th of the time.
} 
Figure 4: Data and Model Estimates

(a) Output Growth

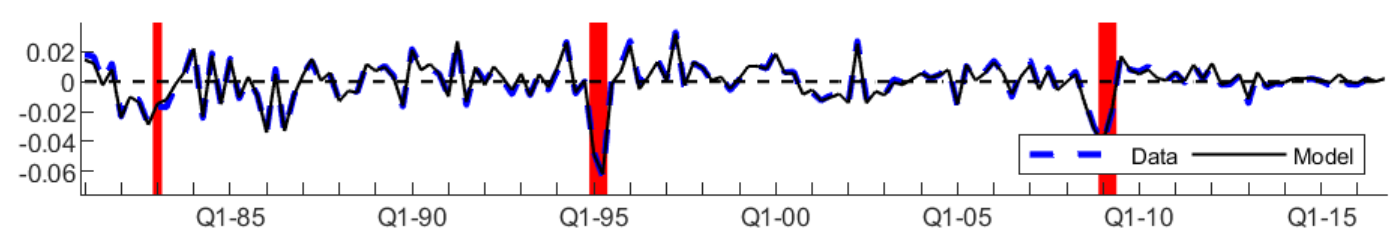

(b) Consumption Growth

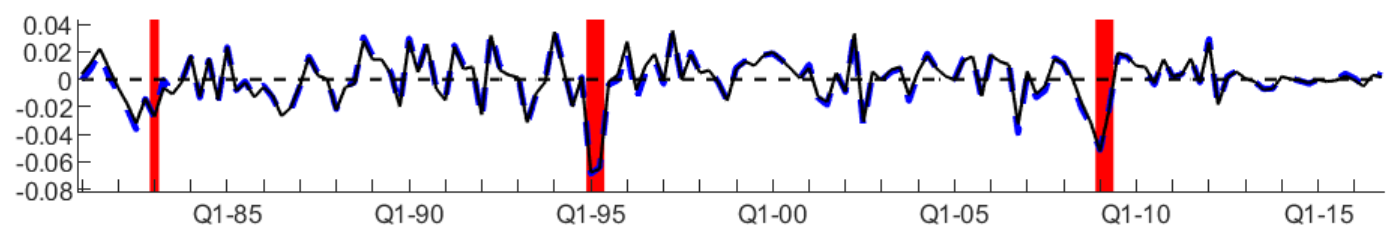

(c) Investment Growth

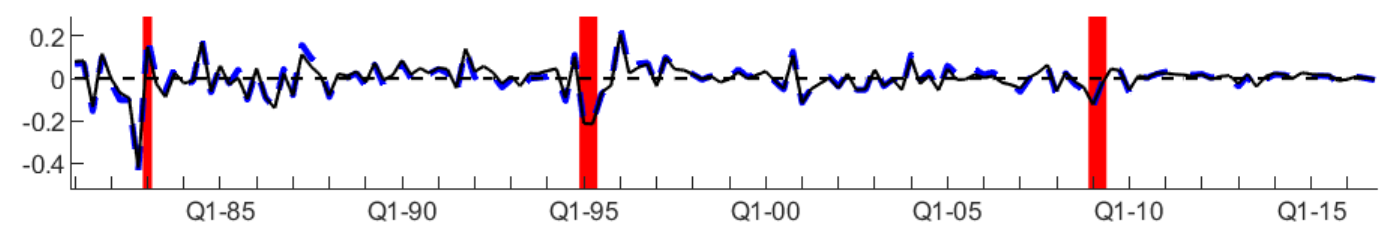

(d) Interest Rate

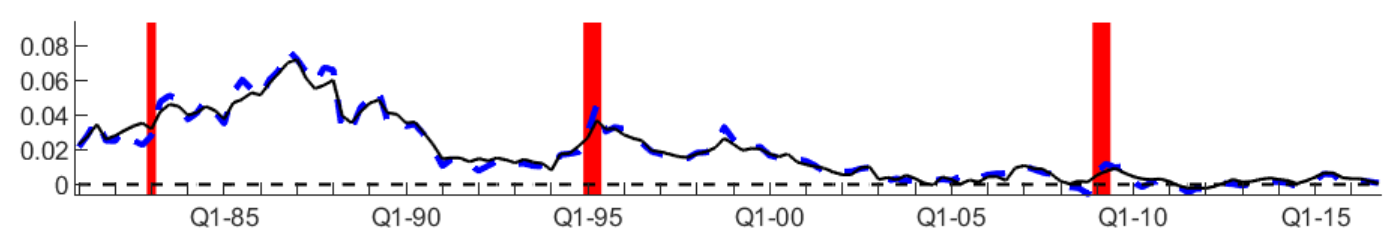

(e) Current Account to Output Ratio

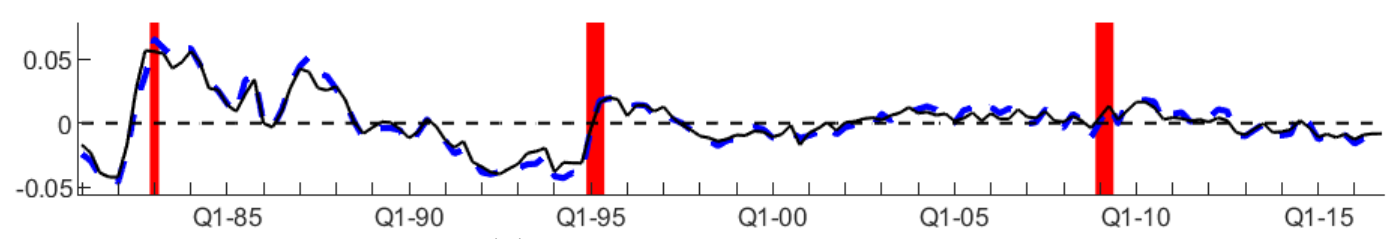

(f) Import Price Growth

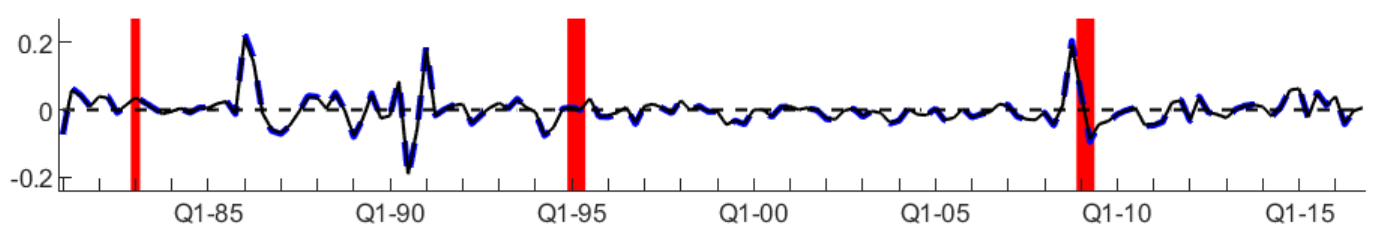

Note: The figure plots observable variables used in estimation (dashed blue lines) and fitted values (i.e., model implied smoothed estimated series based upon the full sample, solid black lines). Red bars indicate model-identified periods of crisis, see text for definition. 
Table 3: Simulated Second Moments: Data and Model

\begin{tabular}{l|cc|cc}
\hline \hline & \multicolumn{2}{|c|}{ Relative Std. Dev. } & \multicolumn{2}{c}{ Correlations } \\
Data Series & Data & Model & Data & Model \\
\hline Output Growth & 1.00 & 1.00 & 1.00 & 1.00 \\
Consumption Growth & 1.25 & 1.92 & 0.73 & 0.98 \\
Investment Growth & 5.37 & 5.75 & 0.53 & 0.90 \\
\hline Trade Balance to Output Ratio & 1.24 & 0.80 & -0.20 & -0.21 \\
Country Interest Rate & 1.36 & 0.15 & -0.11 & -0.03 \\
\hline \hline
\end{tabular}

Notes: The table compares second moments of the data, relative to the same moments simulated from the model.

\subsection{The Anatomy of Business Cycles}

In our third set of results, we discuss second moments to characterize the estimated model dynamics and variance decompositions to identify key drivers of the business cycle. ${ }^{21}$ All statistics reported are unconditional, rather than conditional on a particular regime.

Table 3 compares data and simulated model second moments, reporting results for three variables used in estimation (output, consumption, investment and the country interest rate), and one critical variable, the trade balance ratio, not used in estimation. The model matches the business cycle moments quite well, fitting both the relative volatilities and the correlations with output. The volatility ranking is correct, with consumption significantly more volatile than output, which is a robust stylized fact of emerging market business cycles. The model underestimates the relative volatility or the trade balance ratio and, particularly, the country interest rate. The model implied comovements of all variables match the data counterparts remarkably well, again with the exception of the country interest rate, whose correlation is not estimated precisely in the model. The trade balance, in particular, which is not an observable variable used in estimation, is counter-cyclical as in the data, with a model-implied autocorrelation coefficient (not reported) well below one.

Table 4 reports variance decompositions. The table illustrates that all shocks play a quantitatively sizable role in the model, even though different shocks matter more

\footnotetext{
${ }^{21}$ All business cycle and crisis statistics in this and the following section relying on simulated data. For these simulations, based on the posterior mode estimates, we generate 10,000 samples of 144 quarters length (the same as our data sample), after a burn-in period of 1,000 quarters. We then compute and report median values across these 10,000 runs. We use a pruning method (Andreasen et al., 2018) to avoid explosive simulation paths.
} 
Table 4: Estimated Unconditional Variance Decomposition

\begin{tabular}{l|cccccc}
\hline \hline & & & Import & & Temp. & Pers. \\
Variables / Shocks & TFP & Expend. & Prices & Pref. & Int. Rate & Int. Rate \\
\hline Output & 33.2 & 17.2 & 15.7 & 25.4 & 2.5 & 6.0 \\
Consumption & 30.3 & 23.4 & 14.3 & 20.6 & 3.8 & 7.6 \\
Investment & 19.2 & 29.8 & 10.3 & 25.6 & 4.6 & 10.5 \\
\hline Trade Bal/Output & 9.5 & 35.2 & 8.8 & 17.2 & 9.2 & 20.1 \\
Interest Rate & 0.0 & 0.0 & 0.0 & 0.0 & 21.1 & 78.9 \\
\hline Borrowing Cush. & 10.6 & 32.3 & 9.9 & 21.3 & 9.9 & 16.0 \\
Debt/Output & 15.2 & 25.5 & 7.6 & 40.9 & 1.4 & 9.5 \\
Multiplier & 9.5 & 40.5 & 9.5 & 18.1 & 9.6 & 12.8 \\
\hline \hline
\end{tabular}

Note: The variance decomposition is normalized to sums to 100 by row; estimates may not add up to 100 exactly due to rounding. The decomposition is computed by setting each shock to zero to compute its marginal impact on each variable. The computation abstracts from non-linear interactions across shocks for ease of comparison with linear models.

for different variables. Output and consumption are mostly driven by productivity, preference, expenditure, and terms of trade shocks, respectively. Investment is significantly affected by expenditure, preference, productivity, terms of trade, and persistent interest rate shocks. Expenditure and persistent interest rate shocks are the most important drivers of the trade balance, while the country interest rate is clearly driven by persistent interest rate shocks, and to a lesser extent by the temporary component of the cost of borrowing. Demand shocks (expenditure and preference) and interest rate shocks (permanent and temporary components) play a more important role than productivity and terms of trade shocks for financial variables and the multiplier.

While the magnitude of these variance shares are not directly comparable with those estimated by Garcia-Cicco et al. (2010), Fernandez and Gulan (2015), and Schmitt-Grohe and Uribe (2018), they suggest that both real and financial shocks matter for Mexico business cycles. In particular, we find a lower share for productivity and interest rate shocks than Fernandez and Gulan (2015), although we also consider terms of trade and demand shocks. We also find a share of variance explained by terms of trade shocks that is very close to the structural vector autoregression model estimated by Schmitt-Grohe and Uribe (2018). The estimated share of the variances explained by interest rates shocks is in general smaller than those estimated by GarciaCicco et al. (2010), who use a different specification of the financial friction with a debt elastic country premium and a risk premium shock, without amplification 
mechanism from the financial accelerator (Fernandez and Gulan, 2015), or working capital (Neumeyer and Perri, 2005; Mendoza, 2010; Fernandez and Gulan, 2015; Ates and Saffie, 2016).

\section{The Anatomy of Financial Crises}

In this Section, we turn to our fourth and main set of empirical results, which examine the model's ability to describe and interpret financial crises. The defining feature of our model is its ability to characterize dynamics and identify shocks not only over regular business cycles, but also during periods of a particular type of crisis, the so-called sudden stop in capital flows. We start by defining financial crises episodes in a model consistent manner and discuss the inference that we can draw based on the estimated model about when Mexico appeared to be experiencing them. Next, we investigate the drivers of the three historical episodes of sudden stop that the estimated model identifies in the data: the Debt Crisis of the 1980s, the 1995 'Tequila' Crisis, and the spillover of the Global Financial Crisis (GFC) in 2008-2009. Then we study the model-implied duration and frequency of these episodes in simulations. Finally, we illustrate the model-based dynamics of sudden stop episodes of duration comparable to those realized over Mexico's recent history.

\subsection{Model-based Definition and Estimates of Sudden Stop Episodes}

The estimated model allows us to make inference on whether the economy is in the binding regime, and hence identify periods of sudden stop crisis in a modelconsistent manner. In the model, the regime is known by the household-firm, but the estimation procedure does not observe the regime, and it must be inferred based on the information in the data. The estimation results, therefore, can provide a timevarying estimate of the (smoothed, i.e. based upon the full sample) probability of being in each regime. Figure 5 plots this estimated probability (solid black line). ${ }^{22}$

Using the information in Figure 5, we can provide a model-consistent definition of

\footnotetext{
${ }^{22}$ The estimated model also provides an estimate of the time-varying transition probability based upon equations (14-15). These are reported in Appendix G and confirm that an exogenous regime switching specification would be rejected by the data.
} 
Figure 5: Mexico's Model-identified Crisis Episodes

(a) Probability of Binding Regime and Reinhart-Rogoff Tally Index

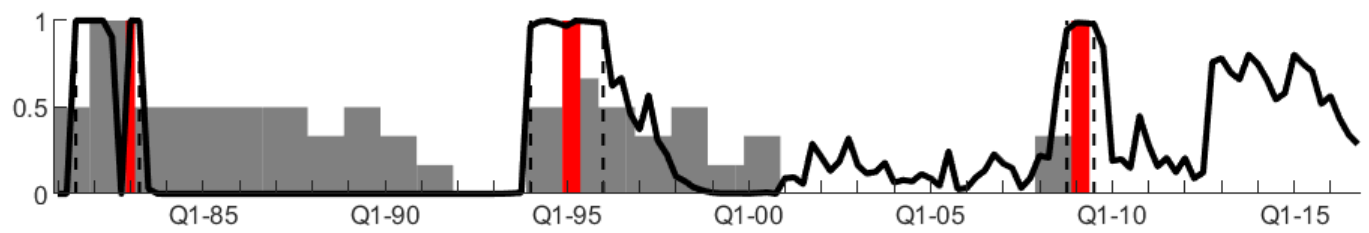

(b) Probability of Binding and OECD Recessions

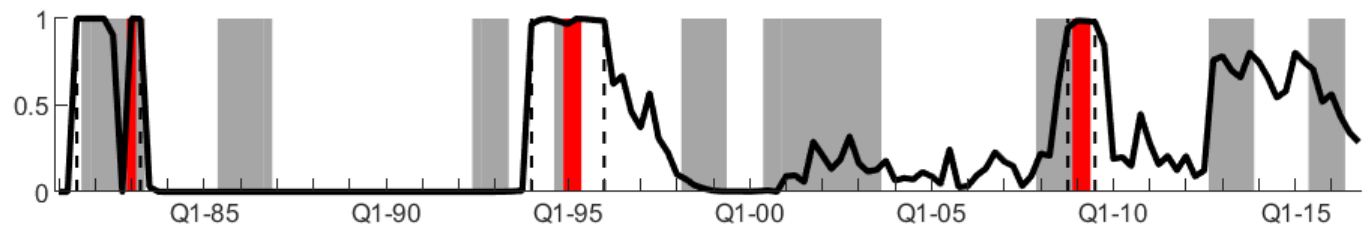

Notes: Black line shows the model implied smoothed probability of being in the binding regime. The dark gray regions in panel (a) indicates Reinhart and Rogoff (2009) tally index of financial crisis, normalized so that it takes values between 0 (no crisis) and 6 (most severe). Light gray regions in panel (b) indicate OECD recession dates for Mexico. Red bars indicate model-identified crisis peaks, vertical blacked dash lines indicate the beginning and the end of the estimated crisis episodes; see text for details.

a crisis quarter as one in which the economy is in the binding regime with probability higher than at least a $90 \%$ probability. ${ }^{23}$ A crisis episode can then be defined as a sequence of such periods. For reference, we also identify the peaks of crisis episodes (red bars) as periods in which (i) the smoothed estimate of the probability of being in the binding regime is at least $90 \%$, (ii) the model estimate of output growth (Figure 4, Panel a) is negative by more than one standard deviation, and (iii) the model estimate of the current account ratio (Figure 4, Panel e) increases by more than one standard deviation. ${ }^{24}$

Figure 5 shows that the model identifies three crisis episodes (start and end quarters marked by vertical dashed lines). The first is the Debt Crisis, which the model identifies as occurring from 1981:Q3-1983:Q2, with an associated peak in 1983:Q1. The second episode is the Tequila Crisis, which the model identifies in 1994:Q1-

${ }^{23}$ This threshold is intuitive but somewhat arbitrary. The duration of the identified sudden stop episode identified, however, is robust to using a wider range of values.

${ }^{24}$ As Figure 4 shows, the identified peak crises periods corresponds to the trough in output, consumption, investment growth in the data, and the peaks in the current account adjustment and interest rate increases. The definition of these crisis peaks in line with the one employed in the quantitative literature modeling sudden stops with occasionally binding constraints (for example, Mendoza, 2010; Benigno et al., 2013). 
1996:Q1, with its peak in 1995:Q1-Q2. Last, the model identifies the GFC as producing a crisis in Mexico during 2008:Q4-2009:Q3, with a peak in 2009:Q1-Q2. Figure 5 also reports a purely empirical definition of financial crisis (dark grey shaded areas in Panel a) and the OECD dating of the business cycle of Mexico (light grey shaded areas in Panel b). The empirical notion of financial crisis reported is a normalized version of the crisis tally index of Reinhart and Rogoff (2009) (RR). ${ }^{25}$ Figure 5 illustrates that our estimated probability of being in a binding regime, which is our model-consistent definition of crisis, align quite well with the RR tally index. The crises episodes that our model identifies track the RR tally index remarkably well in the case of the Tequila and GFC episodes, and are much more persistent than the crisis peaks typically identified in the sudden stop literature. This result is consistent with the idea that our stochastic specification of the borrowing constraint better characterize how lending limits applies to households and firms in the data. Our model's crisis signal is less persistent than the tally index in the aftermath of the Debt crisis. This is to be expected, however, as our model economy is not designed to capture debt overhang or financial intermediation disruptions that drive the classification of RR between 1983 and 1989 and in the mid-1990s.

Importantly, our model estimates of these sudden stop episodes do not mistake ordinary recessions, not associated with spikes in the tally index, for crisis periods. Mexico OECD recessions are illustrated by the light dark shaded areas in Figure 5 Panel (b). The estimated probability of a binding regime is close to 0 during the OECD recessions before the Tequila crisis, during the US recession in 2001, and the Argentine crisis in 2000-2001. The estimated probability of a binding regime also does not register stress during the 1998 Russian default and US Long-Term Capital Management debacle that affected only the currency and stock market, without triggering a sudden stop in Mexico.

Overall, Figure 5 shows that our model provides an accurate signal of when the economy is likely to have experienced a crisis, without mistaking regular recessions or large currency and stock market movements for financial crisis episodes. In the rest

\footnotetext{
${ }^{25}$ The RR tally index ranges from 0 to 6 , depending on whether a country-year observation is deemed to be in one or more of the following 6 varieties of crisis, assigning the value of one if a variety is present: Currency, Inflation, Stock Market, Sovereign Domestic or External Debt, and Banking Crisis. See Chapter 1 of Reinhart and Rogoff (2009) for more details. We follow their methodology to extend the index to cover our full sample. In Figure 5, the index is normalized to range between 0 and 1.
} 
of this section, we study the model-implied properties of these crises episodes-first examining which shocks drove the three identified episodes in Mexico's history, and then studying the frequency and duration and dynamics of model-implied episodes based on simulations.

\subsection{Drivers of Mexico's Sudden Stop Episodes}

Our estimated model fits Mexican data well (Figure 4), including during the crisis episodes identified in Figure 5. We now examine the sudden stop episodes identified by the estimated model, evaluating the relative importance of different shocks driving the economy before, during and after the Debt Crisis of the early 1980s, the Tequila Crisis of 1994-1995, and the spillover on Mexico from the GFC that originated in the United States in 2008-09. This exercise is possible because we have a likelihoodbased estimation of the model that produces sequences of shocks, allowing for the construction of such historical counterfactuals.

The multiple sources of non-linearity in our estimated model, the endogenous regime-switching plus the second-order approximation, pose a challenge for computing historical counterfactuals. The task is complicated by the fact that shocks not only have non-linear effects on the endogenous variables, but also on the realization of the regimes in subsequent periods. Therefore, rather than decomposing the change in endogenous variables such as output, we will focus on a broader summary measure, the importance of each shock in terms of model fit, and hence likelihood.

Specifically, we counterfactually recalculate the model likelihood, evaluated at the posterior mode, turning one shock off at the time, while leaving all other shocks at their estimated values, over a particular sub-sample periods. As the variance decomposition in 4 showed, each shock plays a role in explaining fluctuations unconditionally, with different shocks potentially explaining different variables. Here, we compute the loss of model fit as measured by the log-likelihood change when we turn off one particular shock in a given quarter, and repeat the calculation for all six structural shocks. The details of this calculation are in Appendix G.2.

Table 5 reports a likelihood-based measure of relative importance. As Appendix G.2 documents, the measure is the importance of a shock in a given period relative to all shocks in the model, relative to their importance over the full sample. "Importance" is assessed in terms of likelihood point loss when the shock considered is set to 
Table 5: Estimated Relative Importance of Shocks in Mexico's Crises

\begin{tabular}{|c|c|c|c|c|c|c|}
\hline Time Period & TFP & Exp. & $\begin{array}{l}\text { Imp. } \\
\text { Prices }\end{array}$ & Pref & $\begin{array}{l}\text { Trans } \\
\text { Int Rt. }\end{array}$ & $\begin{array}{l}\text { Persist } \\
\text { Int Rt. }\end{array}$ \\
\hline \multicolumn{7}{|l|}{1983 Debt Crisis } \\
\hline Two Quarters Prior (81:Q1-Q2) & 0.4 & 0.4 & 0.7 & -3.2 & 0.9 & 0.8 \\
\hline During Crisis (81:Q3-83:Q2) & 0.4 & 5.3 & -2.0 & -2.8 & 0.0 & -0.8 \\
\hline Two-years After (83:Q3-85:Q2) & 0.8 & 1.0 & -0.6 & 0.2 & -0.7 & -0.7 \\
\hline \multicolumn{7}{|l|}{1995 Tequila Crisis } \\
\hline Two-years Prior (92:Q1-93:Q4) & -0.1 & -1.0 & 0.4 & 0.7 & 0.1 & -0.1 \\
\hline During Crisis (94:Q1-96:Q1). & -2.2 & -0.7 & 0.5 & 1.3 & 0.2 & 0.9 \\
\hline Two-years After (96:Q2-98:Q1) & -0.1 & -0.2 & 0.2 & 1.1 & -0.6 & -0.4 \\
\hline \multicolumn{7}{|l|}{2009 Global Fin. Crisis } \\
\hline Two-years Prior (06:Q4-08:Q3) & -0.7 & 2.1 & -0.7 & -0.2 & -0.7 & 0.2 \\
\hline During Crisis (08:Q4-09:Q3). & 0.2 & -1.2 & 0.3 & 0.5 & 0.2 & 0.0 \\
\hline Two-years After (09:Q4-11:Q3) & -0.4 & -1.1 & 0.4 & 0.8 & 0.1 & 0.1 \\
\hline
\end{tabular}

Note: The table reports a likelihood-based measure of the importance of each shocs relative to all shocks in the model, during different subperiods, compared to their average relative importance over the full sample, in percentage point differences. For example, a value of +1 indicates the shock has a 1 percentage point greater relative importance in the subsample relative to its average relative importance over the full sample, and indicates a change in the log-likelihood of about 5 points, on average. See Appendix G.2 for details. Bold font highlight the most important shocks in each period according to this metric. Prior period for the 1983 Debt Crisis is limited by the data sample length.

zero. For each of the three crisis episodes, we consider the crisis episodes themselves, as well as two years before and two years after the episode. Positive (negative) numbers denote relatively more (less) important shocks in a given period. For example, a value of +1 means that the shock is relatively more important in that period relative to its average importance over the full sample. A one percentage point change implies a change in the log-likelihood by about $5 \log$ points, on average. By definition, the percentages in Table 5 sum by row.

Consider first the Debt Crisis. Since this episode starts right at the beginning of the sample period, we can only look at the two quarters before its start. The counterfactual analysis suggests that in the immediate run up, the most important shocks were imported intermediate input prices and both temporary and persistent interest rate shocks, consistent with the drop in oil prices starting in 1981 and the Volcker disinflation in the United States. The crisis episode itself and its aftermath 
appears driven by the expenditure and technology shocks, possibly reflecting the import and fiscal contraction typically associated with a sudden stop and its aftermath, and the loss of efficiency associated with sudden adjustment of expenditure plans due to tighter financial frictions.

Next, consider the Tequila Crisis. Our estimated model identified a peak crisis lasting for two quarters in 1995:Q1-Q2. According to our counterfactual results, in the run up to this crisis episode, the most important drivers were the preference shock and imported input price shocks. The importance of these two shocks increases during the crisis episode, even though the shock to the persistent component of the interest rate also becomes more important. The likelihood weight of preference and interest rate shocks declines after the crisis, while the weight in the likelihood of the technology shocks increases during this phase in relative terms. In the post-crisis period, the preference shock continues to play a role, while the importance of shocks to both components of the interest rate decline markedly.

Lastly, consider the GFC episode. The counterfactual likelihood analysis suggests that, before the crisis, expenditure and to a lesser extent a shock to the persistent component of the interest rate were the most important drivers. This is consistent with the lax international financial conditions, strong external demand, and possibly loose fiscal domestic policy prevailing before the GFC. However, all other shocks become more important during the crisis episode itself. In the aftermath of the episode, the likelihood weight of the import price shock and temporary interest rate shock diminishes, while that of the preference and persistent interest shocks increases.

\subsection{Duration and Frequency of Simulated Crisis Episodes}

We now look at the duration and frequency of crisis episodes simulated from the estimated model, shown in Figure $6 .^{26}$ The estimated model generates substantial heterogeneity in crisis duration and frequency. Panel (a) is an histogram of simulated crisis episodes. Given that the shortest of the three estimated crisis episode, the GFC, lasted four quarters, here we consider episodes in which the economy is in the binding regime for at least four consecutive quarters. The average conditional duration is 4.95

\footnotetext{
${ }^{26}$ We simulate 10,000 samples of 144 quarters length, as in our data sample. Note, however, that in these simulations the household-firm always knows in which regime the economy is without sampling uncertainty. Therefore, there is no uncertainty about being in the binding regime, in contrast to the econometrician's perspective reported in Figure 5.
} 
Figure 6: Model-simulated Crisis Duration and Frequency

(a) Conditional Duration: Crisis Episodes of at least Four Consecutive Quarters

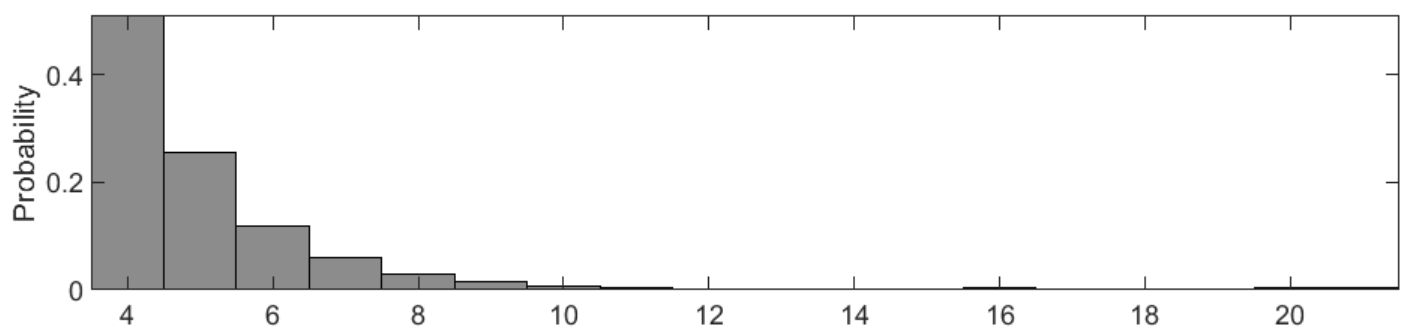

(b) Frequency of Crisis Episodes of Any Duration per Sample

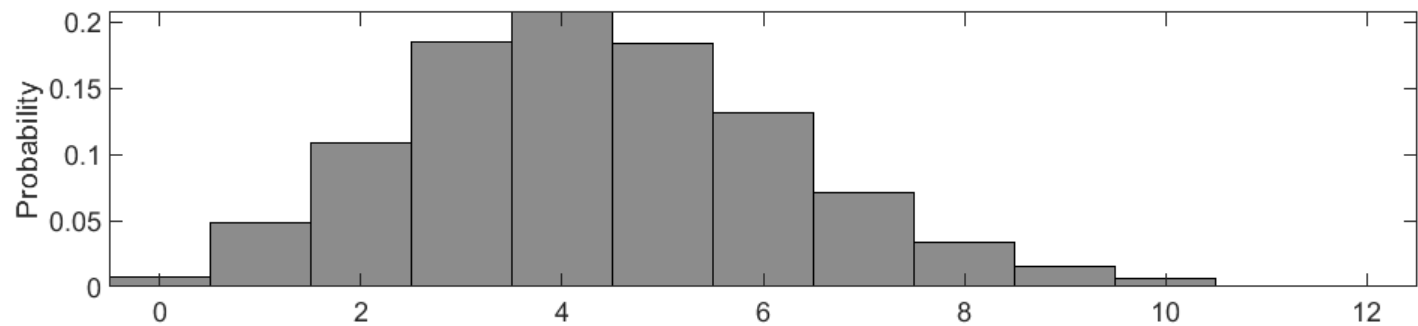

(c) Number of Quarters in Binding Regime per Sample

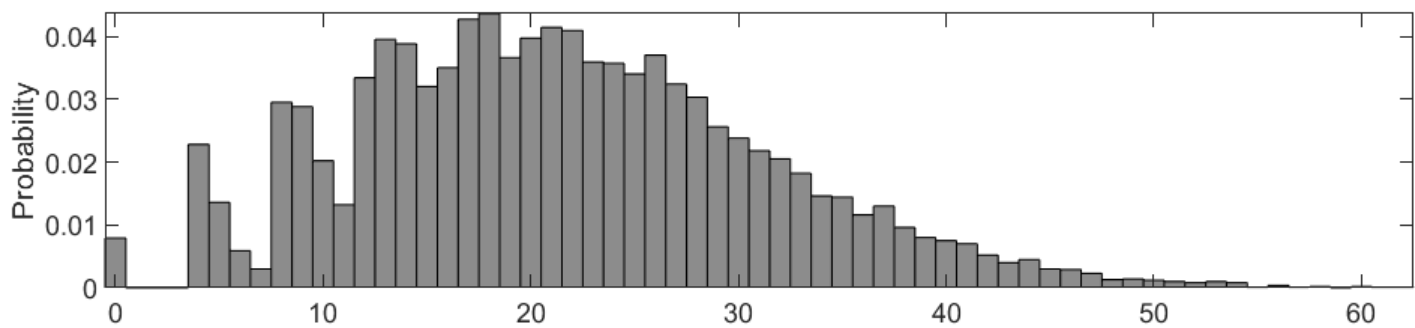

Note: Histograms of the model-implied (a) conditional crisis duration, (b) frequency of distinct episodes of any duration in 144 quarter-long samples, and (c) number of quarters in the binding regime in 144 quarter-long samples.

consecutive quarters in the binding regime. Some of the simulated episodes last up to 22 consecutive quarters though, but they are rare events, as they make up less than a half-percent of all crisis episodes.

Panel (b) counts of crisis episodes of at least four quarters per sample period of 144 quarters length. The most common occurrence is four distinct crisis episodes that is close to our estimation results, which show three distinct events in Mexico's history. However, there is significant heterogeneity, as some samples have no episodes at all, while others experience as many as eight-ten events of short duration per sample.

Building on Panels (a) and (b), Panel (c) counts the total number of quarters 
in crisis episodes out of 144. The model-implied mean is 21.5 quarters, consistent with our estimates in Figure 5, indicating that Mexico spends 21 quarters in crisis on average. The standard deviation, however, is about 10 quarters, with a long right-tail and a maximum of 62 quarters in the binding regime. ${ }^{27}$

\subsection{Dynamics of Model-simulated Crisis Episodes}

We finally turn to model-simulated crisis dynamics shown in Figure 7. As the more severe historical episodes of sudden stop identified in Figure 5 in the early 1980s and mid-1990s lasted about 8 quarters, we report results for episodes of such duration. The Figure plots the model dynamics during crisis episodes of eight consecutive quarters (starting at $t=0$ and ending at $t=7$, vertical dashed lines), as well as 5 years (20 quarters) before the beginning of the episode and 10 years (40 quarters) after the end of the event. Variables are in log-levels, normalized to zero at the beginning of the pre-crisis period that is time $t=-20$.

Figure 7 shows the distinctive combinations of shocks that drive the economy before, during and after the crisis episode. Crisis episodes are preceded by a longlasting "boom" phase, driven by improving technology and a favorable international environment, with improving terms of trade and a persistently lower component of the market interest rate. These three forces drive the expansion gradually, with increasing output, consumption and investment, in a manner consistent with empirical characterizations of the boom phases of financial crises (Boissay et al., 2016).

The economy enters the crisis episode at $t=0$, after a final acceleration, driven by an increase in expenditures and a fall in patience. The crisis episode is precipitated by a sudden reversal of the favorable external environment that drove the boom phase. During the crisis episode, imported intermediate inputs and the market cost of funding increase; the effective cost of borrowing spikes, driven by the external finance premium on debt (EFPD). Technology stagnates and patience increases sharply. The constraint on borrowing limits consumption smoothing and curtail the output supply through the working capital constraint, causing output, consumption and investment to drop sharply. The output drop from peak to through is eight percentage points,

\footnotetext{
${ }^{27}$ Also, when we compute frequency statistics for simulated crisis peaks-the analogous to the red bars in Figure 5-we find a mean frequency of about $2.4 \%$ of the quarters in the binding regime, very close to the typical estimates in the empirical literature on sudden stops (Calvo et al., 2006), but with significant heterogeneity (results not reported).
} 


\section{Figure 7: Dynamics of Crisis Episodes}

(a) Technology

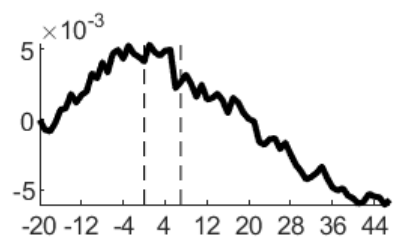

(d) Preference

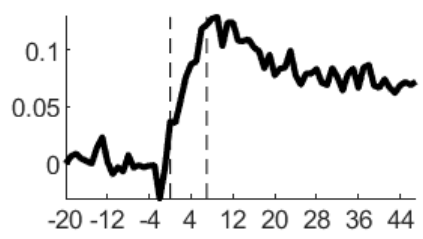

(g) Output

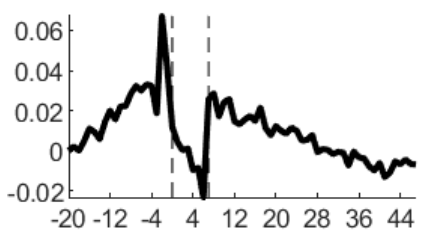

(j) $\mathrm{CA} / \mathrm{Y}$

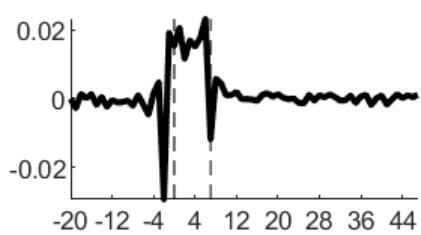

(b) Import Prices

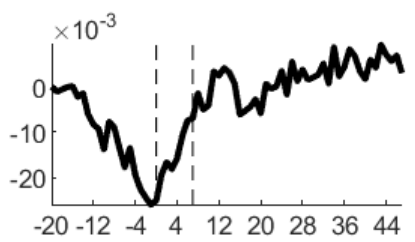

(e) Persist. Int. Rate

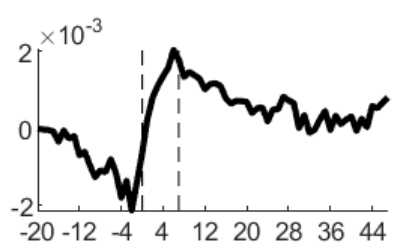

(h) Consumption

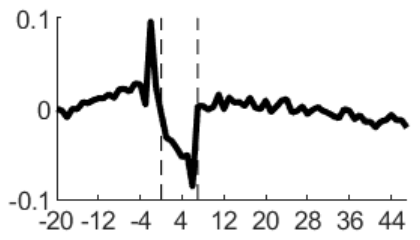

(k) $\mathrm{TB} / \mathrm{Y}$

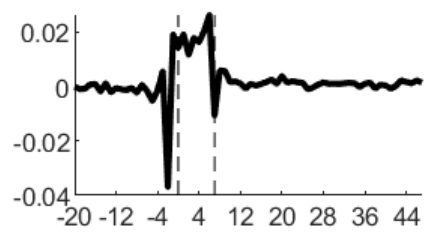

(c) Expenditure

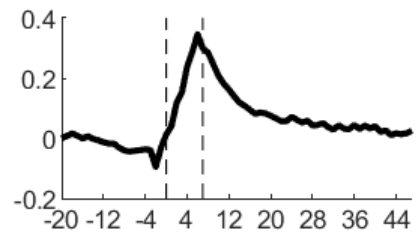

(f) Temp. Int. Rate

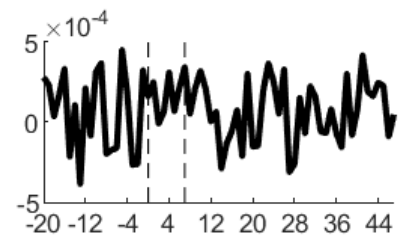

(i) Investment

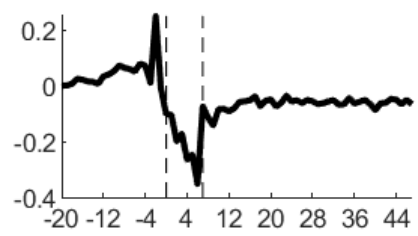

(1) EFPD

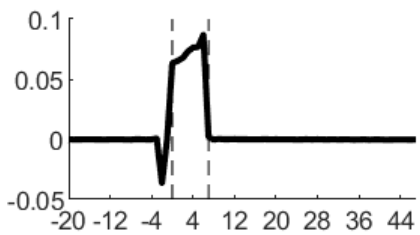

Notes: The figure plot model-simulated dynamics during crisis episodes of eight quarters, five years (20 quarters) before the crisis, and 10 years after the crisis (40 quarters). The economy is in the binding regime from period $t=0$ to period $t=7$ (vertical dashed lines). The plotted dynamics in panels are medians across all crisis episodes identified, in log-levels setting $t-20=0$.

in line with what observed during the Tequila crisis. The trade-balance-to-output ratio suddenly reverts, improving persistently during the crisis phase, after a sharp deterioration right before the beginning of the event, by about six percentage points as a share of output from trough to peak. In line with these dynamics, the autonomous component of expenditure continues to increase during the crisis period, which can be interpreted in terms of the import compression typically associated with sudden stops.

The economy rebounds quickly from these crisis episodes, but only partially, recovering only half of the ground lost during the crisis or about 4 percentage points. 
After the initial rebound, a combination of persistently adverse external and internal circumstances coalesces to produce a protracted output decline, as we can see in the Mexican data after the Debt crisis, and also in line with empirical evidence on the long-term consequences of financial crises in other emerging markets in (Cerra and Saxena, 2008). The cost of borrowing and intermediate imported inputs remains elevated for an extended period of time after the crisis episode. The productivity decline is very long lasting, reaching a significantly lower level compared to before the beginning of the boom phase of the crisis. Expenditure and patience also do not recover to pre-crisis levels ten years after the end of the episode. During the post-crisis period, investment and to a lesser extent consumption stagnate below their pre-crisis levels (Benigno and Fornaro, 2017). As a result, the trade balance remains above its the pre-crisis level long after the crisis has ended.

\section{Conclusions}

In this paper we propose a new approach to specifying and solving Dynamic Stochastic General Equilibrium models with occasionally binding frictions that is suitable for structural estimation. This permits estimating such models using full information methods, obtaining estimates of critical model parameters and conducting likelihoodbased inference and counterfactual experiments. The critical step in our approach is to specify the occasionally binding nature of the friction stochastically, so that the formulation can be mapped into an endogenous regime-switching model.

We apply this new approach to a workhorse medium-scale model of financial crises, the so-called sudden stops in capital flows, and estimate it with Bayesian methods on quarterly data for Mexico since 1981. We find that the estimated model fits Mexico's business cycle and crisis episodes well, critical parameter estimates differ from values previously used in the literature, and that different shocks matter for different variables and phases of financial crisis dynamics. In particular, we show that the model can generate heterogeneous crisis episodes of varying duration, frequency, and intensity. Specific combinations of shocks typically drive the economy before, during, and after crisis episodes, helping to explain why calibrated models of emerging market business cycles perform better assuming that productivity and interest shocks are negatively correlated. Finally, we document that our estimated model identifies sudden stops that are longer lasting and more in line with narratives of Mexico's 
history of financial crises than those typically simulated with traditional inequality specifications of the collateral constraint.

We regard the estimation of larger models-including those with nominal or labor market frictions, those with permanent and temporary productivity shocks over longer sample periods, those with financial intermediation or equilibrium default, and those that embed endogenous probability of infection-as important areas of future research. Such models would be useful lenses to understand episodes like the Great Depression, the Global Financial, and the COVID-19 Crises.

\section{References}

Adam, K. and R. M. Billi (2007). Discretionary Monetary Policy and the Zero Lower Bound on Nominal Interest Rates. Journal of Monetary Economics 54(3), 728-752.

Aguiar, M. and G. Gopinath (2007). Emerging Market Business Cycles: The Cycle Is the Trend. Journal of Political Economy 115, 69-102.

Alpanda, S. and A. Ueberfeldt (2016). Should Monetary Policy Lean Against Housing Market Booms? Staff Working Papers 16-19, Bank of Canada.

Andreasen, M. M., J. Fernandez-Villaverde, and J. F. Rubio-Ramirez (2018). The Pruned State-Space System for Non-Linear DSGE Models: Theory and Empirical Applications. Review of Economic Studies 85(1), 1-49.

Aportela Rodriguez, F., J. A. A. Ituarte, and Y. C. Aguayo (2001). Comportamiento Histrico de Las Tasas de Inters Reales en Mxico: 1951-2001. Documento de Investigacin (Working Paper) No. 2001-0, Direccin General de Investigacin Econmica, Banco de Mexico.

Arellano, C., Y. Bai, and P. Kehoe (2019). Financial Frictions and Fluctuations in Volatility. Journal of Political Economy 127(5), 2049-2103.

Aruoba, B., P. Cuba-Borda, and F. Schorfheide (2018). Macroeconomic Dynamics Near the ZLB: A Tale of Two Countries. Review of Economic Studies 85(1), 87118.

Aruoba, S. B., J. Fernandez-Villaverde, and J. F. Rubio-Ramirez (2006). Comparing Solution Methods for Dynamic Equilibrium Economies. Journal of Economic Dynamics and Control 30(12), 2477-2508.

Ates, S. and F. Saffie (2016). Fewer but Better: Sudden Stops, Firm Entry, and Financial Selection. International Finance Discussion Papers 1187, Board of Governors of the Federal Reserve System (U.S.). 
Atkinson, T., A. W. Richter, and N. Throckmorton (2018). The Zero Lower Bound and Estimation Accuracy. Working Papers 1804, Federal Reserve Bank of Dallas.

Barthlemy, J. and M. Marx (2017). Solving Endogenous Regime Switching Models. Journal of Economic Dynamics and Control 77(C), 1-25.

Benigno, G., H. Chen, C. Otrok, A. Rebucci, and E. Young (2013). Financial Crises and Macro-Prudential Policies. Journal of International Economics 89(2), 453470 .

Benigno, G., H. Chen, C. Otrok, A. Rebucci, and E. R. Young (2016). Optimal Capital Controls and Real Exchange Rate Policies: A Pecuniary Externality Perspective. Journal of Monetary Economics 84(C), 147-165.

Benigno, G. and L. Fornaro (2017). Stagnation Traps. mimeo.

Bi, H. and N. Traum (2014). Estimating Fiscal Limits: The Case Of Greece. Journal of Applied Econometrics 29(7), 1053-1072.

Bianchi, F. (2013). Regime Switches, Agents Beliefs, and Post-World War II U.S. Macroeconomic Dynamics. Review of Economic Studies 80(2), 463-490.

Bianchi, F. and C. Ilut (2017). Monetary/Fiscal Policy Mix and Agents' Beliefs. Review of Economic Dynamics 26, 113-139.

Bianchi, F., C. Ilut, and M. Schneider (2018). Uncertainty Shocks, Asset Supply and Pricing over the Business Cycle. Review of Economic Studies 85(2), 810-854.

Bianchi, J. and E. G. Mendoza (2018). Optimal Time-Consistent Macroprudential Policy. Journal of Political Economy 126(2), 588-634.

Binning, A. and J. Maih (2015). Sigma Point Filters for Dynamic Nonlinear Regime Switching Models. Working Paper 2015/10, Norges Bank.

Binning, A. and J. Maih (2017). Modelling Occasionally Binding Constraints Using Regime-Switching. Working Paper 2017/23, Norges Bank.

Bocola, L. (2016). The Pass-Through of Sovereign Risk. Journal of Political Economy 124(4), 879-926.

Boissay, F., F. Collard, and F. Smets (2016). Booms and Banking Crises. Journal of Political Economy 124, 489-538.

Calvo, G. A., A. Izquierdo, and E. Talvi (2006). Sudden Stops and Phoenix Miracles in Emerging Markets. American Economic Review 96(2), 405-410. 
Campello, M., J. R. Graham, and C. R. Harvey (2010). The Real Effects of Financial Constraints: Evidence from a Financial Crisis. Journal of Financial Economics 97(3), 470-487.

Cerra, V. and S. C. Saxena (2008). Growth Dynamics: The Myth of Economic Recovery. American Economic Review 98(1), 439457.

Chodorow-Reich, G. and A. Falato (2017). The Loan Covenant Channel: How Bank Health Transmits to the Real Economy. Working Papers 23879, NBER.

Cuba-Borda, P., L. Guerrieri, M. Iacoviello, and M. Zhong (2019). Likelihood Evaluation of Models with Occasionally Binding Constraints. Journal of Applied Econometrics 34 (7), 1073-1085.

Davig, T. and E. Leeper (2007). Generalizing the Taylor Principle. American Economic Review 97(3), 607-635.

Davig, T. and E. M. Leeper (2008). Endogenous Monetary Policy Regime Change. In NBER International Seminar on Macroeconomics 2006, NBER Chapters, pp. 345-391. National Bureau of Economic Research, Inc.

Davig, T., E. M. Leeper, and T. B. Walker (2010). "Unfunded Liabilities" and Uncertain Fiscal Financing. Journal of Monetary Economics 57(5), 600-619.

Del Negro, M. and F. Schorfheide (2008). Forming Priors for DSGE Models (and how it Affects the Assessment of Nominal Rigidities). Journal of Monetary Economics 55(7), 1191-1208.

Devereux, M. B., E. Young, and C. Yu (2019). Capital Controls and Monetary Policy in Sudden-stop Economies. Journal of Monetary Economics 103, 52-74.

Eichenbaum, M., S. Rebelo, and M. Trabandt (2020). The Macroeconomics of Epidemics. Working Paper 26882, National Bureau of Economic Research.

Farmer, R., D. Waggoner, and T. Zha (2011). Minimal State Variable Solutions to Markov-Switching Rational Expectations Models. Journal of Economic Dynamics and Control 35(12), 2150-2166.

Fernandez, A. and A. Gulan (2015). Interest Rates, Leverage, and Business Cycles in Emerging Economies: The Role of Financial Frictions. American Economic Journal: Macroeconomics 7(3), 153-188.

Fernandez-Villaverde, J., P. Guerron-Quintana, J. Rubio-Ramirez, and M. Uribe (2011). Risk Matters: The Real Effects of Volatility Shocks. American Economic Review 101(6), 2530-61. 
Fernandez-Villaverde, J., P. Guerron-Quintana, and J. F. Rubio-Ramirez (2015). Estimating Dynamic Equilibrium Models with Stochastic Volatility. Journal of Econometrics 185(1), 216-229.

Fernandez-Villaverde, J. and J. F. Rubio-Ramirez (2007). Estimating Macroeconomic Models: A Likelihood Approach. Review of Economic Studies 74(4), 1059-1087.

Foerster, A. (2015). Financial Crises, Unconventional Monetary Policy Exit Strategies, and Agents Expectations. Journal of Monetary Economics 76(C), 191-207.

Foerster, A., J. F. Rubio-Ramirez, D. F. Waggoner, and T. Zha (2016). Perturbation Methods for Markov-switching Dynamic Stochastic General Equilibrium Models. Quantitative Economics 7(2), 637-669.

Fostel, A. and J. Geanakoplos (2015). Leverage and Default in Binomial Economies: A Complete Characterization. Econometrica 83(6), 2191-2229.

Gabriel, G. (2008). Hechos estilizados del ciclo economico en mexico. Working Paper 2008-14, Banco de Mexico.

Garcia-Cicco, J., R. Pancrazi, and M. Uribe (2010). Real Business Cycles in Emerging Countries? American Economic Review 100(5), 2510-2531.

Gertler, M. and P. Karadi (2011). A Model of Unconventional Monetary Policy. Journal of Monetary Economics 58(1), 17-34.

Gertler, M. and N. Kiyotaki (2015). Banking, Liquidity, and Bank Runs in an Infinite Horizon Economy. American Economic Review 105(7), 2011-2043.

Greenwald, D. (2019). Firm Debt Covenants and the Macroeconomy: The Interest Coverage Channel. Working Paper 5909-19, MIT Sloan.

Guerrieri, L. and M. Iacoviello (2015). OccBin: A Toolkit for Solving Dynamic Models with Occasionally Binding Constraints Easily. Journal of Monetary Economics $70(\mathrm{C}), 22-38$.

Gust, C., E. Herbst, D. Lopez-Salido, and M. Smith (2017). The Empirical Implications of the Interest-Rate Lower Bound. American Economic Review 107(7), 1971-2006.

Iacoviello, M. (2005). House Prices, Borrowing Constraints, and Monetary Policy in the Business Cycle. American Economic Review 95(3), 739-764.

Ivashina, V. and D. Scharfstein (2010). Bank Lending During the Financial Crisis of 2008. Journal of Financial Economics 97(3), 319-338. 
Jermann, U. and V. Quadrini (2012). Macroeconomic Effects of Financial Shocks. American Economic Review 102(1), 238-271.

Jorda, O., M. Schularick, and A. Taylor (2013). When Credit Bites Back: Leverage, Business Cycles, and Crises. Journal of Money, Credit and Banking 45(S2), 3-28.

Julier, S. J. and J. K. Uhlmann (1999). A New Extension of the Kalman Filter to Nonlinear Systems. In Proc. SPIE, Volume 3068, pp. 182-193.

Kim, C.-J. and C. R. Nelson (1999). State-Space Models with Regime Switching: Classical and Gibbs-Sampling Approaches with Applications, Volume 1. The MIT Press.

Kiyotaki, N. and J. Moore (1997). Credit Cycles. Journal of Political Economy 105(2), 211-248.

Kumhof, M., R. Rancire, and P. Winant (2015). Inequality, Leverage, and Crises. American Economic Review 105(3), 1217-1245.

Lind, N. (2014). Regime-Switching Perturbation for Non-Linear Equilibrium Models. Working Paper.

Liu, Z., P. Wang, and T. Zha (2013). Land-Price Dynamics and Macroeconomic Fluctuations. Econometrica 81(3), 1147-1184.

Maih, J. (2015). Efficient Perturbation Methods for Solving Regime-Switching DSGE Models. Working Paper 2015/01, Norges Bank.

Mendoza, E. G. (2010). Sudden Stops, Financial Crises, and Leverage. American Economic Review 100(5), 1941-1966.

Miyamoto, W. and T. L. Nguyen (2017). Business Cycles in Small Open Economies: Evidence from Panel Data between 1900 and 2013. International Economic Review 58(3), 1007-1044.

Neumeyer, P. A. and F. Perri (2005). Business Cycles in Emerging Economies: the Role of Interest Rates. Journal of Monetary Economics 52(2), 345-380.

Otrok, C. (2001). On Measuring the Welfare Cost of Business Cycles. Journal of Monetary Economics 47(1), 61-92.

Reinhart, C. M. and K. S. Rogoff (2009). This Time is Different: Eight Centuries of Financial Folly. Princeton University Press.

Schmitt-Grohe, S. and M. Uribe (2003). Closing Small Open Economy Models. Journal of International Economics 61(1), 163-185. 
Schmitt-Grohe, S. and M. Uribe (2016). Downward Nominal Wage Rigidity, Currency Pegs, and Involuntary Unemployment. Journal of Political Economy 124, 14661514.

Schmitt-Grohe, S. and M. Uribe (2018). How Important are Terms of Trade Shocks? International Economic Review 59(1), 85-111.

Schorfheide, F. (2000). Loss Function-based Evaluation of DSGE Models. Journal of Applied Econometrics 15(6), 645-670.

Smets, R. and F. Wouters (2007). Shocks and Frictions in US Business Cycles: a Bayesian DSGE Approach. American Economic Review 97(3), 586-606.

Uribe, M. and V. Z. Yue (2006). Country Spreads and Emerging Countries: Who Drives Whom? Journal of International Economics 69(1), 6-36.

\section{Appendix A Model and Competitive Equilibrium Definition}

This Appendix derives the model's equilibrium conditions and defines a competitive equilibrium.

\section{A.1 Derivation of Equilibrium Conditions}

The household-firm maximizes the utility function

$$
U \equiv \mathbb{E}_{0} \sum_{t=0}^{\infty}\left\{d_{t} \beta^{t} \frac{1}{1-\rho}\left(C_{t}-\frac{H_{t}^{\omega}}{\omega}\right)^{1-\rho}\right\}
$$

subject to

$$
C_{t}+I_{t}=A_{t} K_{t-1}^{\eta} H_{t}^{\alpha} V_{t}^{1-\alpha-\eta}-P_{t} V_{t}-\phi r_{t}\left(W_{t} H_{t}+P_{t} V_{t}\right)-E_{t}-\frac{1}{\left(1+r_{t}\right)} B_{t}+B_{t-1}
$$

where gross investment follows

$$
I_{t}=\delta K_{t-1}+\left(K_{t}-K_{t-1}\right)\left(1+\frac{\iota}{2}\left(\frac{K_{t}-K_{t-1}}{K_{t-1}}\right)\right)
$$


In the binding regime, the collateral constraint is given by

$$
\frac{1}{\left(1+r_{t}\right)} B_{t}-\phi\left(1+r_{t}\right)\left(W_{t} H_{t}+P_{t} V_{t}\right)=-\kappa q_{t} K_{t}
$$

with the corresponding multiplier denoted $\lambda_{t}$. In the non-binding regime, the collateral constraint disappears, and the multipler is $\lambda_{t}=0$. The first-order conditions of this problem are the following:

$$
\begin{gathered}
d_{t}\left(C_{t}-\frac{H_{t}^{\omega}}{\omega}\right)^{-\rho}=\mu_{t} \\
(1-\alpha-\eta) A_{t} K_{t-1}^{\eta} H_{t}^{\alpha} V_{t}^{-\alpha-\eta}=P_{t}\left(1+\phi r_{t}+\frac{\lambda_{t}}{\mu_{t}} \phi\left(1+r_{t}\right)\right) \\
\alpha A_{t} K_{t-1}^{\eta} H_{t}^{\alpha-1} V_{t}^{1-\alpha-\eta}=\phi W_{t}\left(r_{t}+\frac{\lambda_{t}}{\mu_{t}}\left(1+r_{t}\right)\right)+H_{t}^{\omega-1} \\
\mu_{t}=\lambda_{t}+\beta\left(1+r_{t}\right) \mathbb{E}_{t} \mu_{t+1} \\
\mathbb{E}_{t} \mu_{t+1} \beta\left(\begin{array}{c}
1-\delta+\left(\frac{\iota}{2}\left(\frac{K_{t+1}}{K_{t}}\right)^{2}-\frac{\iota}{2}\right) \\
+\eta A_{t+1} K_{t}^{\eta-1} H_{t+1}^{\alpha} V_{t+1}^{1-\eta-\alpha}
\end{array}\right)=\mu_{t}\left(1-\iota+\iota\left(\frac{K_{t}}{K_{t-1}}\right)\right)-\lambda_{t} \kappa q_{t}
\end{gathered}
$$

Market prices for capital and labor satisfy the following two conditions:

$$
\begin{gathered}
q_{t}=1+\iota\left(\frac{K_{t}-K_{t-1}}{K_{t-1}}\right) \\
W_{t}=H_{t}^{\omega-1} .
\end{gathered}
$$

Defining the borrowing cushion, $B_{t}^{*}$, as the difference between the amount of borrowing and the debt limit

$$
B_{t}^{*}=\frac{1}{\left(1+r_{t}\right)} B_{t}-\phi\left(1+r_{t}\right)\left(W_{t} H_{t}+P_{t} V_{t}\right)+\kappa q_{t} K_{t}
$$


the regime-switching slackness condition is given by

$$
\varphi\left(s_{t}\right) B_{s s}^{*}+\nu\left(s_{t}\right)\left(B_{t}^{*}-B_{s s}^{*}\right)=\left(1-\varphi\left(s_{t}\right)\right) \lambda_{s s}+\left(1-\nu\left(s_{t}\right)\right)\left(\lambda_{t}-\lambda_{s s}\right)
$$

where $\varphi\left(s_{t}\right)$ and $\nu\left(s_{t}\right)$ are regime-switching parameters controlling the level and the dynamics of the economy, respectively, $B_{s s}^{*}$ and $\lambda_{s s}$ are the regime-switching steadystate values of $B_{t}^{*}$ and $\lambda_{t}$.

As we discussed in the text, the country interest rate and the exogenous processes are given by

$$
r_{t}=r_{t}^{*}+\sigma_{r} \varepsilon_{r, t}+\psi_{r}\left(e^{\bar{B}-B_{t}}-1\right)
$$

where

$$
\begin{gathered}
r_{t}^{*}=\left(1-\rho_{r^{*}}\right) \bar{r}^{*}+\rho_{r^{*}} r_{t-1}^{*}+\sigma_{r^{*}} \varepsilon_{r^{*}, t} \\
\log A_{t}=\rho_{A} \log A_{t-1}+\sigma_{A} \varepsilon_{A, t} \\
\log E_{t}=\left(1-\rho_{E}\right) \log E^{*}+\rho_{E} \log E_{t-1}+\sigma_{E} \varepsilon_{E, t} \\
\log P_{t}=\left(1-\rho_{P}\right) \log P^{*}+\rho_{P} \log P_{t-1}+\sigma_{P} \varepsilon_{P, t} \\
\log d_{t}=\rho_{d} \log d_{t-1}+\sigma_{d} \varepsilon_{d, t},
\end{gathered}
$$

where the errors terms $\varepsilon_{\cdot, t}$ are i.i.d $N(0,1)$.

In the paper, we also use a number of auxiliary variables defined as as

$$
\begin{gathered}
\text { GDP: } Y_{t}=A_{t} K_{t-1}^{\eta} H_{t}^{\alpha} V_{t}^{1-\alpha-\eta}-P_{t} V_{t} \\
\text { Debt-to-GDP Ratio: } \Phi_{t}^{b}=\frac{B_{t}}{Y_{t}} \\
\text { Current Account-to-GDP Ratio: } \Phi_{t}^{c a}=\frac{B_{t}-B_{t-1}}{Y_{t}} \\
\text { Trade Balance-to-GDP Ratio: } \Phi_{t}^{t b}=\frac{Y_{t}-E_{t}-C_{t}-I_{t}}{Y_{t}}
\end{gathered}
$$


External Financing Premium on Debt: $E F P D_{t}=\frac{\lambda_{t}}{\beta \mathbb{E}_{t} \mu_{t+1}}$.

\section{A.2 Regime-Switching Equilibrium Definition}

A competitive equilibrium of our economy is a sequence of quantities $\left\{K_{t}, B_{t}, C_{t}\right.$, $\left.H_{t}, V_{t}, I_{t}, A_{t}, E_{t}, B_{t}^{*}\right\}$ and prices $\left\{P_{t}, r_{t}^{*}, r_{t}, q_{t}, w_{t}, \mu_{t}, \lambda_{t}\right\}$ that, given the 5 exogenous processes (A.16)-(A.15), satisfy the first-order conditions for the representative household-firm (A.5)-(A.9), the market price equations (A.10)-(A.11), the market clearing conditions (A.2)-(A.3), the debt cushion definition (A.12), regime-switching slackness condition (A.13), and the equation for the interest rate (A.14).

\section{Appendix B Details of the Perturbation Solution Method}

This Appendix provides details about two aspects of the solution method: (1) the definition of, and solution for, the steady state of the endogenous regime-switching economy; and (2) the perturbation method that generates second order Taylor expansions to the solution of the economy around the steady state.

\section{B.1 Regime Switching Equilibrium}

Write the 23 equilibrium conditions above as

$$
\mathbb{E}_{t} f\left(\mathbf{y}_{t+1}, \mathbf{y}_{t}, \mathbf{x}_{t}, \mathbf{x}_{t-1}, \chi \varepsilon_{t+1}, \varepsilon_{t}, \theta_{t+1}, \theta_{t}\right)=0
$$

Here $\mathbf{y}_{t}$ denotes the non-predetermined variables, $\mathbf{x}_{t}$ predetermined variables, $\varepsilon_{t}$ the exogenous shocks, $\theta_{t}$ the regime-switching parameters, and $\chi$ the perturbation parameter.

There are 7 predetermined variables

$$
\mathbf{x}_{t-1}=\left[K_{t-1}, B_{t-1}, A_{t-1}, P_{t-1}, E_{t-1}, d_{t-1}, r_{t-1}^{*}\right]
$$


and 16 non-predetermined variables

$$
\mathbf{y}_{t}=\left[C_{t}, H_{t}, V_{t}, I_{t}, k_{t}, r_{t}, q_{t}, W_{t}, \mu_{t}, \lambda_{t}, B_{t}^{*}, Y_{t}, \Phi_{t}^{b}, \Phi_{t}^{c a}, \Phi_{t}^{t b}, E F P D_{t}\right]
$$

with 6 exogenous shocks

$$
\varepsilon_{t}=\left[\varepsilon_{A, t}, \varepsilon_{E, t}, \varepsilon_{P, t}, \varepsilon_{d, t}, \varepsilon_{r, t}, \varepsilon_{r^{*}, t}\right]
$$

and 2 regime-switching parameters

$$
\theta_{t}=\left[\varphi\left(s_{t}\right), \nu\left(s_{t}\right)\right]
$$

In general, these variables are partitioned into those that affect the steady state, $\theta_{1, t}$, and those that do not, $\theta_{2, t}$. In the case of our specific application, the partition is

$$
\theta_{1, t}=\left[\varphi\left(s_{t}\right)\right] \quad \theta_{2, t}=\left[\nu\left(s_{t}\right)\right]
$$

In order to solve the model, we assume the functional forms

$$
\begin{gathered}
\theta_{1, t+1}=\bar{\theta}_{1}+\chi \hat{\theta}_{1}\left(s_{t+1}\right), \quad \theta_{1, t}=\bar{\theta}_{1}+\chi \hat{\theta}_{1}\left(s_{t}\right) \\
\theta_{2, t+1}=\theta_{2}\left(s_{t+1}\right), \quad \theta_{2, t}=\theta_{2}\left(s_{t}\right) \\
\mathbf{x}_{t}=h_{s_{t}}\left(\mathbf{x}_{t-1}, \varepsilon_{t}, \chi\right) \\
\mathbf{y}_{t}=g_{s_{t}}\left(\mathbf{x}_{t-1}, \varepsilon_{t}, \chi\right), \quad \mathbf{y}_{t+1}=g_{s_{t+1}}\left(\mathbf{x}_{t}, \chi \varepsilon_{t+1}, \chi\right)
\end{gathered}
$$

and

$$
\mathbb{P}_{s_{t}, s_{t+1}, t}=\pi_{s_{t}, s_{t+1}}\left(\mathbf{y}_{t}\right)
$$

Now, substituting these functional forms in the 23 equilibrium conditions and being more explicit about the expectation operator, given $\left(\mathbf{x}_{t-1}, \varepsilon_{t}, \chi\right)$ and $s_{t}$, we 
have:

$$
F_{s_{t}}\left(\mathbf{x}_{t-1}, \varepsilon_{t}, \chi\right)=\int \sum_{s^{\prime}=0}^{1} \pi_{s_{t}, s^{\prime}}\left(g_{s_{t}}\left(\mathbf{x}_{t-1}, \varepsilon_{t}, \chi\right)\right) f\left(\begin{array}{c}
g_{s_{t+1}}\left(h_{s_{t}}\left(\mathbf{x}_{t-1}, \varepsilon_{t}, \chi\right), \chi \varepsilon^{\prime}, \chi\right), \\
g_{s_{t}}\left(\mathbf{x}_{t-1}, \varepsilon_{t}, \chi\right), \\
h_{s_{t}}\left(\mathbf{x}_{t-1}, \varepsilon_{t}, \chi\right), \\
\mathbf{x}_{t-1}, \chi \varepsilon^{\prime}, \varepsilon_{t}, \\
\bar{\theta}+\chi \hat{\theta}\left(s^{\prime}\right), \bar{\theta}+\chi \hat{\theta}\left(s_{t}\right)
\end{array}\right) d \mu \varepsilon^{\prime}
$$

where $d \mu \varepsilon^{\prime}$ denotes the joint pdf of the shocks.

Finally, stacking all conditions by regime yields:

$$
\mathbb{F}\left(\mathbf{x}_{t-1}, \varepsilon_{t}, \chi\right)=\left[\begin{array}{c}
F_{s_{t}=0}\left(\mathbf{x}_{t-1}, \varepsilon_{t}, \chi\right) \\
F_{s_{t}=1}\left(\mathbf{x}_{t-1}, \varepsilon_{t}, \chi\right)
\end{array}\right]=0
$$

\section{B.2 Steady State Definition and Solution}

The model has two features that make defining a steady state challenging. First, as it is common in a regime-switching framework, some structural parameters may be switching. In the case of our application, there is only one switching parameter that affects the steady state, $\varphi\left(s_{t}\right)$. Nonetheless, in principle, one could allow for regime switching also in the parameters of the exogenous processes, $a^{*}\left(s_{t}\right)$ and $p^{*}\left(s_{t}\right)$, or the structural parameter $\kappa^{*}\left(s_{t}\right)$, which would affect the level of the economy and the steady state calculations. ${ }^{28}$ Following Foerster et al. (2016), we define the steady state in terms of the ergodic means of these parameters across regimes. To define the steady state, we set $\varepsilon_{t}=0$ and $\chi=0$, which implies that the steady state is given by

$$
f\left(\mathbf{y}_{s s}, \mathbf{y}_{s s}, \mathbf{x}_{s s}, \mathbf{x}_{s s}, 0,0, \bar{\theta}_{\mathbf{1}}, \theta_{2}\left(s^{\prime}\right), \bar{\theta}_{1}, \theta_{2}(s)\right)=0
$$

for all $s^{\prime}, s$.

In our case, the transition matrix evaluated at steady state $\mathbb{P}_{s s}$ is endogenous, since it depends on variables that in turn depend on the steady state value of the transition matrix. To find a solution for the steady state, we proceed in two steps.

\footnotetext{
${ }^{28} \mathrm{As}$ is well known, over finite periods of time, unit root processes and processes with structural break or regime changes are observationally equivalent from a statistical standpoint. Allowing for regime changes in the process for $A_{t}$, therefore, would be a way to accommodate permanent productivity shocks as in Aguiar and Gopinath (2007). Similarly, stochastic volatility could be allowed for by introducing regime switching in the some or all of the shock variances.
} 
First, we assume the steady state transition matrix is known and solve for all the steady state prices and quantities. Second, we use the steady state values of the borrowing cushion $B_{s s}^{*}$ and multiplier $\lambda_{s s}$ from Step 1 to update the steady state transition matrix. We then iterate to convergence.

Step 1: Solve steady state using a given steady state transition matrix. First, assume that the steady state transition matrix at iteration $i, \mathbb{P}_{s s}^{(i)}$, is known. Next, let $\xi=\left[\xi_{0}, \xi_{1}\right]$ denote the ergodic vector of $\mathbb{P}_{s s}^{(i)}$. Then, as noted in the paper, define the ergodic means of the switching parameters as

$$
\bar{\varphi}=\xi_{0} \varphi(0)+\xi_{1} \varphi(1) .
$$

The steady state of the regime-switching economy depends on these ergodic means, and we can now solve for the steady states of all variables. First, we can partially solve for some of the steady state directly

$$
A_{s s}=1, d_{s s}=1, E_{s s}=E^{*}, P_{s s}=P^{*}, q_{s s}=1, r_{s s}^{*}=\bar{r}^{*}
$$

Suppose now that we knew $r_{s s}$. Then, we can obtain:

$$
\begin{gathered}
\Omega_{v} \equiv \frac{A_{s s} K_{s s}^{\eta} H_{s s}^{\alpha} V_{s s}^{1-\alpha-\eta}}{P_{s s} V_{s s}}=\frac{1+\phi r_{s s}+\phi\left(1+r_{s s}\right)\left(1-\beta\left(1+r_{s s}\right)\right)}{1-\alpha-\eta} \\
\Omega_{h} \equiv \frac{A_{s s} K_{s s}^{\eta} H_{s s}^{\alpha} V_{s s}^{1-\alpha-\eta}}{W_{s s} H_{s s}}=\frac{1+\phi\left(r_{s s}+\left(1+r_{s s}\right)\left(1-\beta\left(1+r_{s s}\right)\right)\right)}{\alpha} \\
\Omega_{k} \equiv \frac{A_{s s} K_{s s}^{\eta} H_{s s}^{\alpha} V_{s s}^{1-\alpha-\eta}}{K_{s s}}=\frac{1}{\eta}\left(\frac{1-\kappa\left(1-\beta\left(1+r_{s s}\right)\right)}{\beta}-1+\delta\right) \\
H_{s s}=\left(\frac{A_{s s}}{\Omega_{k}^{\eta} \Omega_{h}^{\alpha}\left(P_{s s} \Omega_{v}\right)^{1-\alpha-\eta}}\right)^{\frac{1}{\alpha(\omega-1)}} \\
V_{s s} \equiv \frac{\Omega_{h}}{P_{s s} \Omega_{v}} H_{s s}^{\omega} \\
K_{s s}=\frac{\Omega_{h}}{\Omega_{k}} H_{s s}^{\omega}
\end{gathered}
$$




$$
\begin{aligned}
& Y_{s s}=\Omega_{h} H_{s s}^{\omega}-P_{s s} V_{s s} \\
& W_{s s}=H_{s s}^{\omega-1} \\
& I_{s s}=\delta K_{s s} \\
& k_{s s}=K_{s s} \\
& B_{s s}=\bar{B}-\log \left(1+\frac{r_{s s}-r^{*}}{\psi_{r}}\right) \\
& C_{s s}=Y_{s s}-\phi r_{s s}\left(W_{s s} H_{s s}+P_{s s} V_{s s}\right)-E_{s s}+B_{s s}\left(1-\frac{1}{\left(1+r_{s s}\right)}\right)-I_{s s} \\
& \mu_{s s}=\left(C_{s s}-\frac{H_{s s}^{\omega}}{\omega}\right)^{-\rho} \\
& \lambda_{s s}=\left(1-\beta\left(1+r_{s s}\right)\right) \mu_{s s} \\
& B_{s s}^{*}=\frac{1}{\left(1+r_{s s}\right)} B_{s s}-\phi\left(1+r_{s s}\right)\left(W_{s s} H_{s s}+P_{s s} V_{s s}\right)+\kappa K_{s s} \\
& \Phi_{s s}^{b}=\frac{B_{s s}}{Y_{s s}} \\
& \Phi_{s s}^{c a}=0 \\
& \Phi_{s s}^{t b}=\frac{Y_{s s}-E_{s s}-C_{s s}-I_{s s}}{Y_{s s}} \\
& E F P D_{s s}=\frac{\lambda_{s s}}{\beta \mu_{s s}}
\end{aligned}
$$


The variable $r_{s s}$ can then be derived as the solution of

$$
\bar{\varphi} B_{s s}^{*}=(1-\bar{\varphi}) \lambda_{s s} .
$$

Step 2: Updating the transition matrix. Step 1 yields the variables $B_{s s}^{*}$ and $\lambda_{s s}$, and hence provides a new value of the transition matrix for iteration $i+1$ :

$$
P_{s s}^{(i+1)}=\left[\begin{array}{ll}
p_{00, s s} & p_{01, s s} \\
p_{10, s s} & p_{11, s s}
\end{array}\right]=\left[\begin{array}{cc}
1-\frac{\exp \left(-\gamma_{0} B_{s s}^{*}\right)}{1+\exp \left(-\gamma_{0} B_{s s}^{*}\right)} & \frac{\exp \left(-\gamma_{0} B_{s s}^{*}\right)}{1+\exp \left(-\gamma_{s s} B_{s s}^{*}\right)} \\
\frac{\exp \left(-\gamma_{1} \lambda_{s s}\right)}{1+\exp \left(-\gamma_{1} \lambda_{s s}\right)} & 1-\frac{\exp \left(-\gamma_{1} \lambda_{s s}\right)}{1+\exp \left(-\gamma_{1} \lambda_{s s}\right)}
\end{array}\right],
$$

which can be checked against the guess in Step 1. We then iterate to convergence until

$$
\left\|P_{s s}^{(i+1)}-P_{s s}^{(i)}\right\|<\text { tolerance, }
$$

where in our application we use a tolerance of $10^{-10}$.

\section{B.3 Generating Approximations}

To compute a second order approximation to the endogenous regime-switching model solution, we largely follow Foerster et al. (2016), adapting to the case with endogenous probabilities.

We take the stacked equilibrium conditions $\mathbb{F}\left(\mathbf{x}_{t-1}, \varepsilon_{t}, \chi\right)$, and differentiate with respect to $\left(\mathbf{x}_{t-1}, \varepsilon_{t}, \chi\right)$. The first-order derivative with respect to $\mathbf{x}_{t-1}$ produces a complicated polynomial system denoted

$$
\mathbb{F}_{\mathbf{x}}\left(\mathbf{x}_{s s}, \mathbf{0}, 0\right)=0 .
$$

In Foerster et al. (2016), when the transition probabilities are exogenous and fixed, this system needs to be solved via Gröbner bases, which finds all possible solutions in order to check them for stability. In our case with endogenous probabilities, the standard stability checks fail, so we will focus on finding a single solution and ignore the possibility of indeterminacy, a common simplification in the regime-switching literature with and without endogenous switching (e.g. Farmer et al., 2011; Foerster, 2015; Maih, 2015; Lind, 2014). Ignoring the possibility of multiple equilibria is also common in models with occasionally binding constraints. Global solution methods of models with occasionally binding constraint also do not guarantee uniqueness, and 
the focus typically is on checking robustness of the solution to initial conditions (for example, Mendoza, 2010; Benigno et al., 2013; Bianchi and Mendoza, 2018).

To find a model solution, we guess a set of policy functions for regime $s_{t}=1$, which reduces the equilibrium conditions $\mathbb{F}_{\mathbf{x}}\left(\mathbf{x}_{s s}, \mathbf{0}, 0 ; s_{t}=0\right)$ to a fixed-regime eigenvalue problem, and solve for the policy functions for $s_{t}=0$. Then, using this initial solution as a guess, we solve for regime $s_{t}=0$ under the fixed-regime eigenvalue problem, and iterate to convergence. After solving the iterative eigenvalue problem, the remaining systems to solve are

$$
\begin{aligned}
& \mathbb{F}_{\varepsilon}\left(\mathbf{x}_{s s}, \mathbf{0}, 0\right)=0 \\
& \mathbb{F}_{\chi}\left(\mathbf{x}_{s s}, \mathbf{0}, 0\right)=0
\end{aligned}
$$

and the second order systems of the form

$$
\mathbb{F}_{\mathbf{i}, \mathbf{j}}\left(\mathbf{x}_{s s}, \mathbf{0}, 0\right)=0, \mathbf{i}, \mathbf{j} \in\{\mathbf{x}, \varepsilon, \chi\}
$$

Recalling now that the decision rules have the form

$$
\begin{aligned}
& \mathbf{x}_{t}=h_{s_{t}}\left(\mathbf{x}_{t-1}, \varepsilon_{t}, \chi\right) \\
& \mathbf{y}_{t}=g_{s_{t}}\left(\mathbf{x}_{t-1}, \varepsilon_{t}, \chi\right),
\end{aligned}
$$

the second-order approximation are

$$
\begin{aligned}
& \mathbf{x}_{t} \approx \mathbf{x}_{s s}+H_{s t}^{(1)} S_{t}+\frac{1}{2} H_{s_{t}}^{(2)}\left(S_{t} \otimes S_{t}\right) \\
& \mathbf{y}_{t} \approx \mathbf{y}_{s s}+G_{s_{t}}^{(1)} S_{t}+\frac{1}{2} G_{s_{t}}^{(2)}\left(S_{t} \otimes S_{t}\right)
\end{aligned}
$$

where $S_{t}=\left[\begin{array}{lll}\left(\mathbf{x}_{t-1}-\mathbf{x}_{s s}\right)^{\prime} & \varepsilon_{t}^{\prime} & 1\end{array}\right]^{\prime}$, with $\mathbf{x}_{s s}$ denoting the value of the steady-state variables. 


\section{B.4 Proposition 1: Irrelevance of Endogenous Switching in the First-Order Solution}

To prove Proposition 1, take the first-order derivatives of (B.13) with respect to its arguments, evaluated at the steady state. This yields:

$$
\begin{gathered}
\mathbb{F}_{\mathbf{x}, s_{t}}\left(\mathbf{x}_{s s}, \mathbf{0}, 0\right)=+\sum_{s^{\prime}} \pi_{s t, s^{\prime}, y}\left(\mathbf{y}_{s s}\right) g_{\mathbf{x}, s_{t}} f_{s s}\left(s^{\prime}, s_{t}\right) \\
+\sum_{s_{t}, s^{\prime}}\left(\mathbf{y}_{s s}\right)\left[\begin{array}{c}
f_{\mathbf{y}_{t+1}}\left(s^{\prime}, s_{t}\right) g_{\mathbf{x}, s^{\prime}} h_{\mathbf{x}, s_{t}}+f_{\mathbf{y}_{t}}\left(s^{\prime}, s_{t}\right) g_{\mathbf{x}, s_{t}} \\
+f_{\mathbf{x}_{t}}\left(s^{\prime}, s_{t}\right) h_{\mathbf{x}, s_{t}}+f_{\mathbf{x}_{t-1}}\left(s^{\prime}, s_{t}\right)
\end{array}\right] \\
\mathbb{F}_{\varepsilon, s_{t}}\left(\mathbf{x}_{s s}, \mathbf{0}, 0\right)= \\
+\sum_{s^{\prime}} \pi_{s_{t}, s^{\prime}}\left(\mathbf{y}_{s s}\right)\left[\begin{array}{c}
f_{\mathbf{y}_{t+1}}\left(s^{\prime}, s_{t}\right) g_{\mathbf{x}, s^{\prime}} h_{\varepsilon, s_{t}}+f_{\mathbf{y}_{t}}\left(s^{\prime}, s_{t}\right) g_{\varepsilon, s_{t}} \\
+f_{\mathbf{x}_{t}}\left(s^{\prime}, s_{t}\right) h_{\varepsilon, s_{t}}+f_{\varepsilon_{t}}\left(s^{\prime}, s_{t}\right)
\end{array}\right]
\end{gathered}
$$

and

$$
\mathbb{F}_{\chi, s_{t}}\left(\mathbf{x}_{s s}, \mathbf{0}, 0\right)=+\sum_{s^{\prime}} \pi_{s_{t}, s^{\prime}}\left(\mathbf{y}_{s s}\right)\left[\begin{array}{c}
\sum_{s^{\prime}} \pi_{s_{t}, s^{\prime}, y}\left(\mathbf{y}_{s s}\right) g_{\chi, s_{t}} f_{s s}\left(s^{\prime}, s_{t}\right) \\
\mathbf{y}_{t+1}\left(s^{\prime}, s_{t}\right) g_{\mathbf{x}, s^{\prime}} h_{\chi, s_{t}}+f_{\mathbf{y}_{t}}\left(s^{\prime}, s_{t}\right) g_{\chi, s_{t}} \\
+f_{\mathbf{x}_{t}}\left(s^{\prime}, s_{t}\right) h_{\chi, s_{t}} \\
+f_{\theta_{t+1}}\left(s^{\prime}, s_{t}\right) \hat{\theta}\left(s_{t+1}\right)+f_{\theta_{t}}\left(s^{\prime}, s_{t}\right) \hat{\theta}\left(s_{t}\right)
\end{array}\right] .
$$

Note now that, by definition of a steady state, $f_{s s}\left(s^{\prime}, s_{t}\right)=0$, and so the first term of each of these expressions equals zero. Hence, we are left with the expressions for the exogenous transition probabilities as in Foerster et al. (2016), given by $\mathbb{P}_{s s}=$ $\pi_{s_{t}, s^{\prime}}\left(\mathbf{y}_{s s}\right)$. QED.

\section{Appendix C Accuracy of the Solution}

We assess accuracy of the solution by checking the Euler equation error (EEE), where

$$
E E E_{t}=1-\frac{\lambda_{t}}{\mu_{t}}-\beta\left(1+r_{t}\right) \mathbb{E}_{t} \frac{\mu_{t+1}}{\mu_{t}}
$$


and the policy functions can be denoted by

$$
\lambda_{t}=\lambda_{s_{t}}\left(\mathbf{x}_{t-1}, \varepsilon_{t}\right), \quad \mu_{t}=\mu_{s_{t}}\left(\mathbf{x}_{t-1}, \varepsilon_{t}\right), \quad r_{t}=r_{s_{t}}\left(\mathbf{x}_{t-1}, \varepsilon_{t}\right), \quad B_{t}^{*}=B_{s_{t}}^{*}\left(\mathbf{x}_{t-1}, \varepsilon_{t}\right) .
$$

So, given $\left(\mathbf{x}_{t-1}, \varepsilon_{t}\right)$

$$
\begin{aligned}
E E E_{s_{t}}\left(\mathbf{x}_{t-1}, \varepsilon_{t}\right)= & 1-\frac{\lambda_{s_{t}}\left(\mathbf{x}_{t-1}, \varepsilon_{t}\right)}{\mu_{s_{t}}\left(\mathbf{x}_{t-1}, \varepsilon_{t}\right)}-\frac{\beta\left(1+r_{s_{t}}\left(\mathbf{x}_{t-1}, \varepsilon_{t}\right)\right)}{\mu_{s_{t}}\left(\mathbf{x}_{t-1}, \varepsilon_{t}\right)} \quad \text { (C.3) } \\
& \times \sum_{s_{t+1}=0}^{1} p_{s_{t, t+1}}\left(\mathbf{x}_{t-1}, \varepsilon_{t}\right) \int_{\mathbb{R}^{\varepsilon}} \mu_{s_{t+1}}\left(\mathbf{x}_{t}, \varepsilon_{t+1}\right) \mu\left(\varepsilon_{t+1}\right) d \varepsilon_{t+1}(\text { C.4 } 4)
\end{aligned}
$$

where $\mathbf{x}_{t-1}$ denotes the predetermined variables and $\varepsilon_{t}$ denotes the shocks.

We simulate the model for 10,000 periods, after a 1,000 burn-in period to get sequences of $s_{t}$ and $\left(\mathbf{x}_{t-1}, \varepsilon_{t}\right)$. For each simulation period, we draw 10,000 values of $\varepsilon_{t+1}$ to compute the integral above. We then average the absolute values, finding errors of approximately $\$ 1$ per $\$ 1,000$ of consumption.

To compare our perturbation-based solution method with global methods we solved a smaller-scale occasionally bonding constraint model, i.e., the model in Jermann and Quadrini (2012), using three different methods. First, we replicate the results in that paper solving the inequality-constraint version of the model with a global projection method. Second, we solve the endogenous regime-switching formulation of that model via the same global projection methods. Third, we solve the endogenous regime-switching formulation with our proposed perturbation method.

Table C.1: Comparing Solution Accuracy: Global vs. Perturbation Methods

\begin{tabular}{l|ccc}
\hline \hline & Inequality & \multicolumn{2}{c}{ Endo Switch } \\
Comparison & Constraint & Global & Perturb. \\
\hline Standard Deviations & & & \\
$\quad$ GDP & 2.38 & 2.46 & 2.28 \\
$\quad$ Hours & 1.36 & 1.46 & 1.33 \\
Autocorrelations & & & \\
$\quad$ GDP & 0.94 & 0.94 & 0.94 \\
$\quad$ Hours & 0.77 & 0.76 & 0.77 \\
Euler Eqn Errors $\left(\log _{10}\right)$ & -10.47 & -3.59 & -3.41 \\
\hline \hline
\end{tabular}

Table C.1 reports some of the results and highlights that these three approaches 
have nearly identical implications for the standard deviations and autocorrelations of GDP and hours, which are two key variables in that model. Furthermore, the Euler equation errors all achieve reasonable levels of accuracy. The traditional inequality constraint solved with global method has the smallest Euler equation errors. However, the endogenous switching model solved globally and the perturbation solution returned accuracy values of -3.6 and -3.4 in log-10 points, respectively. ${ }^{29}$ The latter two numbers suggest an approximation error of $\$ 2.60$ and $\$ 3.90$ per $\$ 10,000$ of consumption. The higher accuracy comes at a significant computational cost, as the global methods solve in minutes, while the perturbation solution takes less than a second. Moreover, we also note here that when Binning and Maih (2017) investigated the properties of our framework with simulated data from other structural models, they found a high degree of accuracy.

\section{Appendix D Estimation Procedure}

\section{D.1 State Space}

For likelihood estimation, the state space representation is

$$
\begin{gathered}
X_{t}=\mathcal{H}_{s_{t}}\left(X_{t-1}, \varepsilon_{t}\right) \\
y_{t}=\mathcal{G}_{s_{t}}\left(X_{t}, \mathcal{U}_{t}\right)
\end{gathered}
$$

where $x_{t}$ denotes the state, $y_{t}$ denotes the observation, $\varepsilon_{t}$ denotes the structural shocks, and $\mathcal{U}_{t}$ denotes the observation errors.

Recall the second-order approximation takes the form

$$
\begin{aligned}
& \mathbf{x}_{t} \approx \mathbf{x}_{s s}+H_{s_{t}}^{(1)} S_{t}+\frac{1}{2} H_{s_{t}}^{(2)}\left(S_{t} \otimes S_{t}\right) \\
& \mathbf{y}_{t} \approx \mathbf{y}_{s s}+G_{s_{t}}^{(1)} S_{t}+\frac{1}{2} G_{s_{t}}^{(2)}\left(S_{t} \otimes S_{t}\right)
\end{aligned}
$$

\footnotetext{
${ }^{29}$ Note that this value can be driven down further by optimizing the number of gridpoints in our global solution algorithm.
} 
where $S_{t}=\left[\begin{array}{lll}\left(\mathbf{x}_{t-1}-\mathbf{x}_{s s}\right)^{\prime} & \varepsilon_{t}^{\prime} & 1\end{array}\right]^{\prime}$. Therefore, we can define the state variables as

$$
x_{t}=\left[\begin{array}{lllll}
\mathbf{x}_{t}^{\prime} & \mathbf{x}_{t-1}^{\prime} & \mathbf{y}_{t}^{\prime} & \mathbf{y}_{t-1}^{\prime} & \epsilon_{t}
\end{array}\right]^{\prime}
$$

The nonlinear transition equations,

$$
X_{t}=\mathcal{H}_{s t}\left(X_{t-1}, \varepsilon_{t}\right)
$$

can be represented as

$$
\left[\begin{array}{c}
\mathbf{x}_{t} \\
\mathbf{x}_{t-1} \\
\mathbf{y}_{t} \\
\mathbf{y}_{t-1} \\
\varepsilon_{t}
\end{array}\right]=\left[\begin{array}{c}
\mathbf{x}_{s s}+H_{s_{t}}^{(1)} S_{t}+\frac{1}{2} H_{s_{t}}^{(2)}\left(S_{t} \otimes S_{t}\right) \\
\mathbf{x}_{t-1} \\
\mathbf{y}_{s s}+G_{s_{t}}^{(1)} S_{t}+\frac{1}{2} G_{s_{t}}^{(2)}\left(S_{t} \otimes S_{t}\right) \\
\mathbf{y}_{t-1} \\
\varepsilon_{t}
\end{array}\right]
$$

The observation equation

$$
y_{t}=\mathcal{G}_{s_{t}}\left(X_{t}, \mathcal{U}_{t}\right)
$$

is given by

$$
\left[\begin{array}{c}
\Delta y_{t} \\
\Delta c_{t} \\
\Delta i_{t} \\
r_{t} \\
\Delta B_{t} / Y_{t} \\
\Delta P_{t}
\end{array}\right]=D\left[\begin{array}{c}
\mathbf{x}_{t} \\
\mathbf{x}_{t-1} \\
\mathbf{y}_{t} \\
\mathbf{y}_{t-1} \\
\varepsilon_{t}
\end{array}\right]+\mathcal{U}_{t}
$$

where $D$ denotes a selection matrix of the form

$$
\left[\begin{array}{c}
\Delta y_{t} \\
\Delta c_{t} \\
\Delta i_{t} \\
r_{t} \\
\Delta B_{t} / Y_{t} \\
\Delta P_{t}
\end{array}\right]=\left[\begin{array}{ccccc}
0 & 0 & 1_{\left[y_{t}\right]} & -1_{\left[y_{t}\right]} & 0 \\
0 & 0 & 1_{\left[c_{t}\right]} & -1_{\left[c_{t}\right]} & 0 \\
0 & 0 & 1_{\left[i_{t}\right]} & -1_{\left[i_{t}\right]} & 0 \\
0 & 0 & 1_{\left[r_{t}\right]} & 0 & 0 \\
0 & 0 & 1_{\left[\Phi_{t}^{c a}\right]} & 0 & 0 \\
1_{\left[P_{t}\right]} & -1_{\left[P_{t}\right]} & 0 & 0 & 0
\end{array}\right]\left[\begin{array}{c}
\mathbf{x}_{t} \\
\mathbf{x}_{t-1} \\
\mathbf{y}_{t} \\
\mathbf{y}_{t-1} \\
\varepsilon_{t}
\end{array}\right]+\mathcal{U}_{t} .
$$




\section{D.2 Filtering}

To filter the likelihood, we use the Unscented Kalman Filter (UKF). The UKF calculates the state mean and covariance by propagating deterministically chosen sigmapoints through the nonlinear functions. The transformed points are then used to calculate the mean and covariance matrix. As Julier and Uhlmann (1999) note, the critical assumption taken to apply the UKF is that the prediction density and the filtering density are both Gaussian.

The filtering and smoothing largely follow Binning and Maih (2015). The filter starts by combining the state vector and exogenous disturbances into a single vector, $X_{t-1}^{a}=\left[X_{t-1}, \epsilon_{t}\right]^{\prime}$, with the following mean and covariance matrix conditional on $Y_{1: t-1}$ and regime $s_{t-1}$ :

$$
\begin{gathered}
X_{t-1}^{a}\left(s_{t-1}\right)=\left[\begin{array}{c}
X_{t-1 \mid t-1}\left(s_{t-1}\right) \\
0_{\epsilon}
\end{array}\right] \\
P_{t-1}^{a}\left(s_{t-1}\right)=\left[\begin{array}{cc}
P_{t-1 \mid t-1}^{x}\left(s_{t-1}\right) & 0 \\
0 & I
\end{array}\right] .
\end{gathered}
$$

The sigma-points $X_{i, t-1}^{a}\left(s_{t-1}\right)$ that consist of the sigma-points for state variables $X_{i, t-1}^{x}\left(s_{t-1}\right)$ and the sigma-points for exogenous shocks $X_{i, t-1}^{\varepsilon}\left(s_{t-1}\right)$ are chosen as follows:

$$
\begin{aligned}
& X_{0, t-1}^{a}\left(s_{t-1}\right)=X_{t-1}^{a}\left(s_{t-1}\right) \\
& X_{0, t-1}^{a}\left(s_{t-1}\right)=X_{t-1}^{a}\left(s_{t-1}\right) \\
& X_{i, t-1}^{a}\left(s_{t-1}\right)=X_{t-1}^{a}\left(s_{t-1}\right)+\left(h \sqrt{P_{t-1}^{a}\left(s_{t-1}\right)}\right)_{i} \text { for } i=1 \ldots L \\
& X_{i, t-1}^{a}\left(s_{t-1}\right)=X_{t-1}^{a}\left(s_{t-1}\right)-\left(h \sqrt{P_{t-1}^{a}\left(s_{t-1}\right)}\right)_{i-L} \text { for } i=L+1 \ldots 2 L,
\end{aligned}
$$

where $h=\sqrt{3}$ and $L$ denotes the number of state variables and exogenous shocks. The weights for the sigma-points are given by:

$$
\begin{aligned}
& w_{0}=\frac{h-L}{2 h} \\
& w_{i}=\frac{1}{2 h} \text { for } i=1 \ldots 2 L
\end{aligned}
$$

The sigma-points and the assigned weights are used to calculate the expected mean and covariance by propagating sigma-points through transition equations and 
taking weighted average:

$$
\begin{gathered}
X_{i, t \mid t-1}\left(s_{t-1}, s_{t}\right)=H_{s_{t}}\left(X_{i, t-1}^{x}\left(s_{t-1}\right), X_{i, t-1}^{\varepsilon}\left(s_{t-1}\right)\right) \\
x_{t \mid t-1}\left(s_{t-1}, s_{t}\right)=\sum_{i=0}^{2 L} w_{i} X_{i, t \mid t-1}\left(s_{t-1}, s_{t}\right) \\
P_{t \mid t-1}^{x}\left(s_{t-1}, s_{t}\right)=\sum_{i=0}^{2 L} w_{i} \tilde{X}_{i} \tilde{X}_{i}^{T} \\
y_{t \mid t-1}\left(s_{t-1}, s_{t}\right)=D X_{t \mid t-1}\left(s_{t-1}, s_{t}\right)
\end{gathered}
$$

where $\tilde{X}_{i}=X_{i, t \mid t-1}\left(s_{t-1}, s_{t}\right)-X_{t \mid t-1}\left(s_{t-1}, s_{t}\right)$. From these conditions, we get the Gaussian approximation predictive density $p\left(X_{t} \mid \mathcal{Y}_{1: t-1}, s_{t-1}, s_{t}\right)=N\left(\mathcal{X}_{t \mid t-1}\left(s_{t-1}, s_{t}\right), P_{t \mid t-1}^{x}\left(s_{t-1}, s_{t}\right)\right)$. The predictive density is then updated using the standard Kalman filter rule:

$$
\begin{gathered}
P_{t \mid t-1}^{y}\left(s_{t-1}, s_{t}\right)=D P_{t \mid t-1}^{x}\left(s_{t-1}, s_{t}\right) D^{T}+R \\
P_{t \mid t-1}^{x y}\left(s_{t-1}, s_{t}\right)=P_{t \mid t-1}^{x}\left(s_{t-1}, s_{t}\right) D^{T} \\
K_{t}\left(s_{t-1}, s_{t}\right)=P_{t \mid t-1}^{x y}\left(s_{t-1}, s_{t}\right)\left(P_{t \mid t-1}^{y}\left(s_{t-1}, s_{t}\right)\right)^{-1} \\
X_{t \mid t}\left(s_{t-1}, s_{t}\right)=X_{t \mid t-1}\left(s_{t-1}, s_{t}\right)+K_{t}\left(s_{t-1}, s_{t}\right)\left(y_{t}-y_{t \mid t-1}\left(s_{t-1}, s_{t}\right)\right) \\
P_{t \mid t}^{x}\left(s_{t-1}, s_{t}\right)=P_{t \mid t-1}^{x}\left(s_{t-1}, s_{t}\right)-K_{t}\left(s_{t-1}, s_{t}\right) P_{t \mid t-1}^{y}\left(s_{t-1}, s_{t}\right) K_{t}^{T}\left(s_{t-1}, s_{t}\right)
\end{gathered}
$$

This updating step gives $p\left(\mathcal{X}_{t} \mid \mathcal{y}_{1: t}, s_{t-1}, s_{t}\right)=N\left(\mathcal{X}_{t \mid t}\left(s_{t-1}, s_{t}\right), P_{t \mid t}^{x}\left(s_{t-1}, s_{t}\right)\right)$. As a by-product of the filter, we can get the density of $y_{t}$ conditional on $y_{1: t-1}, s_{t}$, and $s_{t-1}$

$$
p\left(y_{t} \mid y_{1: t-1}, s_{t-1}, s_{t} ; \theta\right)=N\left(y_{t \mid t-1}\left(s_{t-1}, s_{t}\right), P_{t \mid t-1}^{y}\left(s_{t-1}, s_{t}\right)\right)
$$

Since the Unscented Kalman filter with regime switches creates a large number of nodes at each iteration where the filtered mean and covariance matrix need to be evaluated, we implement the following collapsing procedure suggested by Kim and 
Nelson (1999)

$$
\begin{gathered}
X_{t \mid t}\left(s_{t}=j\right)=\frac{1}{\operatorname{Pr}\left(s_{t}=j \mid y_{1: t}\right)}\left\{\sum_{i=1}^{M} \operatorname{Pr}\left(s_{t-1}=i, s_{t}=j \mid y_{1: t}\right) X_{t \mid t}\left(s_{t-1}=i, s_{t}=j\right)(\mathcal{D} .29)\right. \\
P_{t \mid t}^{x}\left(s_{t}=j\right)=\frac{1}{\operatorname{Pr}\left(s_{t}=j \mid y_{1: t}\right)}\left\{\sum _ { i = 1 } ^ { M } \operatorname { P r } ( s _ { t - 1 } = i , s _ { t } = j | y _ { 1 : t } ) \left[P_{t \mid t}^{x}\left(s_{t-1}=i, s_{t}=6 \mathrm{D} .30\right)\right.\right. \\
\left.\left.+\left(X_{t \mid t}\left(s_{t}=j\right)-X_{t \mid t}\left(s_{t-1}=i, s_{t}=j\right)\right)\left(X_{t \mid t}\left(s_{t}=j\right)-X_{t \mid t}\left(s_{t-1}=i, s_{t}=j\right)\right)^{T}\right]\right\}
\end{gathered}
$$

where $\operatorname{Pr}\left(s_{t}, s_{t-1} \mid y_{1: t}\right)$ and $\operatorname{Pr}\left(s_{t} \mid y_{1: t}\right)$ are obtained from the following Hamilton filter

$$
\begin{gathered}
\operatorname{Pr}\left(s_{t}, s_{t-1} \mid y_{1: t-1}\right)=\operatorname{Pr}\left(s_{t} \mid s_{t-1}\right) \operatorname{Pr}\left(s_{t-1} \mid y_{1: t-1}\right) \\
\operatorname{Pr}\left(s_{t}, s_{t-1} \mid y_{1: t}\right)=\frac{p\left(y_{t} \mid s_{t}, s_{t-1}, y_{1: t-1}\right) \operatorname{Pr}\left(s_{t}, s_{t-1} \mid y_{1: t-1}\right)}{\sum_{s_{t}} \sum_{s_{t-1}} p\left(y_{t} \mid s_{t}, s_{t-1}, y_{1: t-1}\right) \operatorname{Pr}\left(s_{t}, s_{t-1} \mid y_{1: t-1}\right)} \\
\operatorname{Pr}\left(s_{t} \mid y_{1: t}\right)=\sum_{s_{t-1}} \operatorname{Pr}\left(s_{t}, s_{t-1} \mid y_{1: t}\right) .
\end{gathered}
$$

The resulting conditional marginal likelihood is

$$
p\left(\boldsymbol{y}_{t} \mid \boldsymbol{y}_{1: t-1} ; \theta\right)=\sum_{s_{t}} \sum_{s_{t-1}} p\left(\boldsymbol{y}_{t} \mid s_{t}, s_{t-1}, \boldsymbol{y}_{1: t-1}\right) \operatorname{Pr}\left(s_{t}, s_{t-1} \mid \boldsymbol{y}_{1: t-1}\right) .
$$

\section{D.3 Smoothing}

Once we perform the filtering using the UKF for $t=1, \ldots, T$, we can also obtain $\operatorname{Pr}\left(s_{t}, s_{t+1} \mid y_{1: T}\right), \operatorname{Pr}\left(s_{t} \mid y_{1: T}\right), x_{t \mid T}\left(s_{t}, s_{T}\right)$, and $P_{t \mid T}^{x}\left(s_{t}, s_{T}\right)$ :

$$
\begin{aligned}
\operatorname{Pr}\left(s_{t}, s_{t+1} \mid y_{1: T}\right) & =\frac{\operatorname{Pr}\left(s_{t+1} \mid y_{1: T}\right) \operatorname{Pr}\left(s_{t} \mid y_{1: t}\right) \operatorname{Pr}\left(s_{t+1} \mid s_{t}\right)}{\operatorname{Pr}\left(s_{t+1} \mid y_{1: t}\right)} \\
\operatorname{Pr}\left(s_{t} \mid y_{1: T}\right) & =\sum_{s_{t+1}} \operatorname{Pr}\left(s_{t}, s_{t+1} \mid y_{1: T}\right) \\
X_{t \mid T}\left(s_{t}, s_{t+1}\right) & =X_{t \mid t}\left(s_{t}\right)+\tilde{K}_{t}\left(s_{t}, s_{t+1}\right)\left(X_{t+1 \mid T}\left(s_{t+1}\right)-X_{t+1 \mid t}\left(s_{t}, s_{t+1}\right)\right) \\
P_{t \mid T}^{x}\left(s_{t}, s_{t+1}\right) & =P_{t \mid t}^{x}\left(s_{t}\right)-\tilde{K}_{t}\left(s_{t}, s_{t+1}\right)\left(P_{t+1 \mid T}^{x}\left(s_{t+1}\right)-P_{t+1 \mid T}^{x}\left(s_{t}, s_{t+1}\right)\right) \tilde{K}_{t}\left(s_{t}, s_{t+1}\right)^{T}
\end{aligned}
$$

Given the above smoothing algorithm, we implement a collapsing procedure sim- 
ilar to those in the filtering step:

$$
\begin{gathered}
x_{t \mid T}\left(s_{t}=j\right)=\frac{1}{\operatorname{Pr}\left(s_{t}=j \mid y_{1: T}\right)}\left\{\sum_{j=1}^{M} \operatorname{Pr}\left(s_{t}=i, s_{t+1}=j \mid y_{1: T}\right) X_{t \mid T}\left(s_{t}=i, s_{t+1}=j\right)\right\} \\
P_{t \mid T}^{x}\left(s_{t}=j\right)=\frac{1}{\operatorname{Pr}\left(s_{t}=j \mid y_{1: T}\right)}\left\{\sum _ { j = 1 } ^ { M } \operatorname { P r } ( s _ { t } = i , s _ { t + 1 } = j | y _ { 1 : T } ) \left[P_{t \mid T}^{x}\left(s_{t}=i, s_{t+1}=j\right)\right.\right. \\
+\left(X_{t \mid T}\left(s_{t}=j\right)-X_{t \mid T}\left(s_{t}=i, s_{t+1}=j\right)\right)\left(X_{t \mid T}\left(s_{t}=j\right)-X_{t \mid T}\left(s_{t}=i, s_{t+1}=j\right)\right)^{T} \text { 拉.39) }
\end{gathered}
$$

\section{Appendix E Calibrated Parameters}

To calibrate the parameters that we do not estimate, we largely follow Mendoza (2010), targeting the same moments, but adapting the computations to our model specification. We start by calibrating certain parameters based on the steady state of the model without working capital and the borrowing constraint-i.e., with $\phi=0$ and $\bar{\varphi}=0$, which implies $\lambda_{s s}=0$. In addition, we set

$$
\beta\left(1+r_{s s}\right)=1
$$

and

$$
\Omega_{v}=\frac{1}{1-\alpha-\eta}, \Omega_{h}=\frac{1}{\alpha}, \Omega_{k}=\frac{1}{\eta}\left(\frac{1}{\beta}-1+\delta\right) .
$$

The implied factor payment ratios are

$$
\begin{gathered}
\frac{P_{s s} V_{s s}}{Y_{s s}+P_{s s} V_{s s}}=\frac{1}{\Omega_{v}}=1-\alpha-\eta \\
\frac{W_{s s} H_{s s}}{Y_{s s}}=\frac{1}{\Omega_{h}\left(1-\frac{1}{\Omega_{v}}\right)}=\frac{\alpha}{\alpha+\eta} \\
\frac{\left(\frac{1}{\beta}-1+\delta\right) K_{s s}}{Y_{s s}}=\frac{\frac{1}{\beta}-1+\delta}{\Omega_{k}\left(1-\frac{1}{\Omega_{v}}\right)}=\frac{\eta}{\alpha+\eta} .
\end{gathered}
$$


Using the National Accounts, we obtain

$$
\left[\begin{array}{c}
1-\alpha-\eta=0.102 \\
\frac{\alpha}{\alpha+\eta}=0.66
\end{array}\right] \Longrightarrow\left[\begin{array}{l}
\alpha=0.59268 \\
\eta=0.30532
\end{array}\right]
$$

We then set the depreciation rate to an annual value of 8.8 percent, so that

$$
(1-\delta)^{4}=1-0.088 \Longrightarrow \delta=0.022766
$$

The capital-to-(gross annual) output ratio is 1.758, so the capital-to-(gross quarterly) output ratio, $\Omega_{k}^{-1}$, implies

$$
\Omega_{k}^{-1}=\left(\frac{1}{\eta}\left(\frac{1}{\beta}-1+\delta\right)\right)^{-1}=4 * 1.758 \Longrightarrow \beta=0.97977
$$

In turn, this yields an annualized real interest rate of

$$
\left(1+r_{s s}\right)^{4}=\left(\frac{1}{\beta}\right)^{4}=1.0852
$$

which is very close to the value used in Mendoza (2010), but it is obtained under different discounting assumptions. From the resource constraint,

$$
\frac{C_{s s}}{Y_{s s}}+\frac{I_{s s}}{Y_{s s}}+\frac{E_{s s}}{Y_{s s}}=1+\left(1-\frac{1}{1+r_{s s}}\right) \frac{B_{s s}}{Y_{s s}},
$$

we obtain

$$
0.65+0.172+0.11=1+(1-\beta) \frac{B_{s s}}{Y_{s s}} \Longrightarrow \frac{B_{s s}}{Y_{s s}}=-3.3605 .
$$

This implies

$$
\frac{B_{s s}}{4 Y_{s s}}=-0.840127
$$

from which we have

$$
Y_{s s}=\frac{\alpha+\eta}{\alpha}\left(\frac{1}{P_{s s}^{1-\alpha-\eta}\left(\frac{1}{\eta}\left(\frac{1}{\beta}-1+\delta\right)\right)^{\eta}\left(\frac{1}{\alpha}\right)^{\alpha}\left(\frac{1}{1-\alpha-\eta}\right)^{1-\alpha-\eta}}\right)^{\frac{\omega}{\alpha(\omega-1)}}=1.8202(\mathrm{E} .13)
$$


and

$$
E^{*}=\frac{E_{s s}}{Y_{s s}} Y_{s s}=0.11 * 1.8202=0.20022
$$

as well as

$$
B_{s s}=-0.840127 * 4 * 1.8202=-6.11685 .
$$

Finally, conditional on $r^{*}$ and $\psi_{r}, \bar{B}$ is pinned down via

$$
\bar{B}=\log \left(1+\frac{r_{s s}-r^{*}}{\psi_{r}}\right)+B_{s s}
$$

\section{Appendix F Data Appendix}

National accounts are from the National Statistic Office. The data series used in the analysis merge two sets of official statistics by updating the level of the accounts based on 1993 constant prices with the quarterly rate of growth of the accounts based on 2008 constant prices. The merging is necessary as the deflators to splice the accounts in levels were not available at the time of last download of the data (May 2017). The two sets of national accounts overlap from 1993:Q1 to 2006:Q4. Over this period, the difference in annual rate of growth is less than 0.01 percent in absolute value for GDP, less than 0.05 percent for consumption, less than 2 percent for investment, and less than 1 and 3 percent for imports and exports, respectively. The correlations between the series are more than 0.9 for all series except investment that is 0.84 , pointing to possibly larger measurement errors in this variable. The differences are smaller the closer to the end of the sample. For this reason, we choose to update the 1993 accounts rather than backdate the 2008 ones.

The specific sources of the data are as follows:

- 1980:Q1-2006:Q4 (Labeled 1993 accounts)-Supply and demand of goods and services. Original Series (not seasonally adjusted). Constant prices, annual $1993=100$. We obtained these from the Central Bank of Mexico (Gabriel, 2008).

- 2006:Q1-2016:Q4 (Labeled 2008 accounts)-Supply and demand of goods and services. Original series (not seasonally adjusted). Constant prices, annual $2008=100$ (Oferta y demanda de bienes y servicios. Series originales. A precios constantes 2008). Available from http://www3.inegi.org.mx/sistemas/ 
tabuladosbasicos/tabdirecto.aspx.

The data are not seasonally adjusted and show a strong seasonal pattern. To seasonally adjust all series (assumed to be I(1) processes), we adjust the log-difference using the X-12 procedure with the additive option in Eviews. We then use the log of the first observation of the raw series (not seasonally adjusted) and cumulate the seasonally adjusted log-difference. The net exports to GDP series, used to validate the model externally but not as an observable variable in estimation, is calculated as real exports minus real imports divided by real GDP.

The current account as a percentage of GDP is from the balance of payment statistics, obtained from the OECD Economic Outlook Database (Series MEX.CBGDPR.Q, OECD-EO-MEX-CBGDPR-Q).

As a proxy for the relative price of intermediate goods, entered as observable in estimation, we use a measure of Mexico's terms of trade obtained from Banco de Mxico (PPI Producer and International Trade Price Indexes, series SP12753).

Mexico's country interest rate is calculated following Uribe and Yue (2006) as

$$
r_{t}=r_{t}^{*}+\text { spread }_{t}
$$

where $r^{*}$ is the US real interest rate, and spread is a proxy for Mexico's country risk or sovereign spread. We compute $r^{*}$ as 3-month Treasury Constant Maturity Rate adjusted for ex post CPI (annualized) quarterly inflation, using period average data. The source of these data is FRED. For the country spread, as customary, we use the Mexico's component of the JP Morgan EMBI.

Unfortunately, the EMBI spread is available only starting from 1993. In order to estimate the country spread before 1993, we rely on empirical modeling of the relation between domestic real interest rates and country risk at the Banco de Mexico (Aportela Rodriguez et al., 2001) that estimates a close and stable relation between a measure of the domestic real interest rate and the EMBI spread over the period over which both these variables are available. The only interest series available going back to 1980 is a three-month nominal short-term rate obtained from Banco de Mexico (Average monthly yield on 90-days Cetes, series SF3338). ${ }^{30}$ So we estimate a relationship between this nominal interest rate, $i_{t}$, and the EMBI during the period over

\footnotetext{
${ }^{30}$ There are three missing monthly observations in this series: August and September 1986 and November 1988. We fill these gaps using July 1986 for 1986Q3 and the average of October and December 1988 for 1988:Q4.
} 
which the EMBI is observable, adjusting for inflation, $\pi_{t}$, which was an important source of nominal interest rate variation in the 1980s, and then invert it. Specifically, we posit the following simplified version of the model that (Aportela Rodriguez et al., 2001) estimate:

$$
i_{t}=\alpha_{0}+\alpha_{1} \pi_{t}+\alpha_{2} E M B I_{t}
$$

We then solve the fitted equation for the country risk component of the domestic real interest rate, which we denote as $E \hat{M B} I_{t}$. The estimated regression is (t-statistics in parentheses and $\left.R^{2}=0.883\right)$ :

$$
\hat{i_{t}}=\underset{(-0.42)}{0.00346}+\underset{(4.46)}{0.397} \pi_{t}+\underset{(7.37)}{2.770 E M B} \hat{M} I_{t}
$$

\section{Appendix G Additional Results}

In this appendix we report additional empirical results.

\section{G.1 Estimated Shocks and Transition Probabilities}

Figure 8 plots the estimated model implied shocks in standard deviation units, together with a two-standard deviations band. The figure shows that the model fit is largely achieved without relying on unusually large shocks, including during crisis times. Shocks slightly outside the two-standard divisions band are estimated right before the 1982 debt crisis, possibly do to the limited number of observations before the peak of that episode. TFP, expenditure, and preference shocks, however, are all well within the band during the that event.

Figure 9 plots the pseudo-real-time (i.e. filtered) estimated transition probabilities; panel (a) shows the probability of switching from the non-binding to the binding regime, while panel (b) shows the probability of switching from the binding to the non-binding regime. In other words, they plot the estimated counterpart of the transition probabilities together with the model identified crisis peaks. These probabilities provide the odds of switching from one regime to the other as the model travels through the sample. Their behavior is driven by the estimated parameters $\gamma_{0}$ and $\gamma_{1}$ and the estimated values of $B^{*}$ and $\lambda$. Both probabilities are time-varying and hence suggest that a model with exogenous and constant switching probabilities would be 
Figure 8: Model Estimated Shocks

(a) TFP Shock

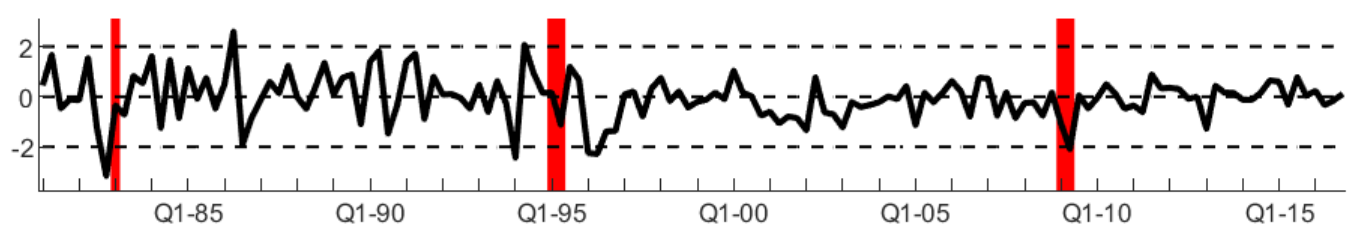

(b) Expenditure Shock

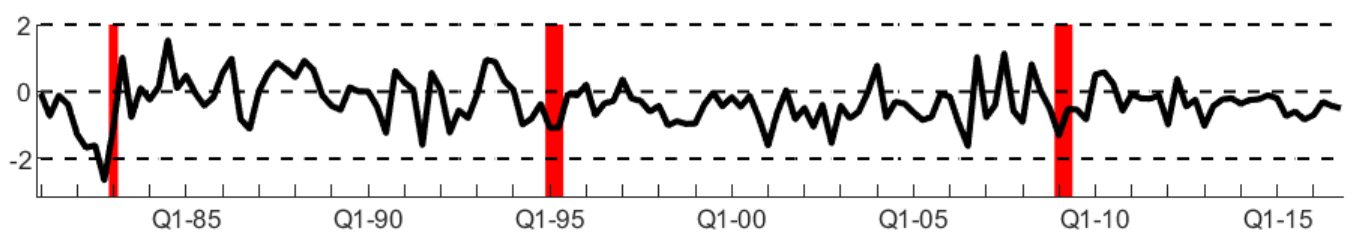

(c) Import Price Shock

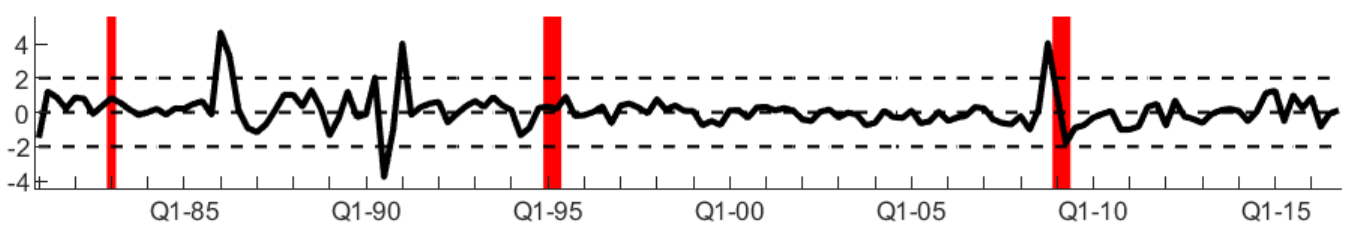

(d) Preference Shock

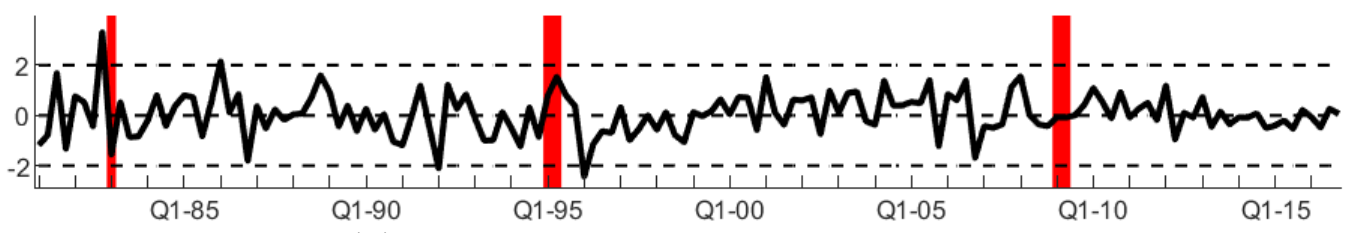

(e) Transitory Interest Rate Shock

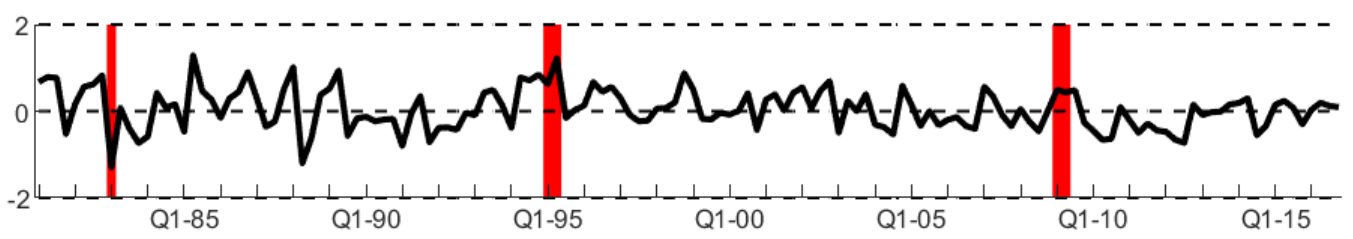

(f) Persistent Interest Rate Shock

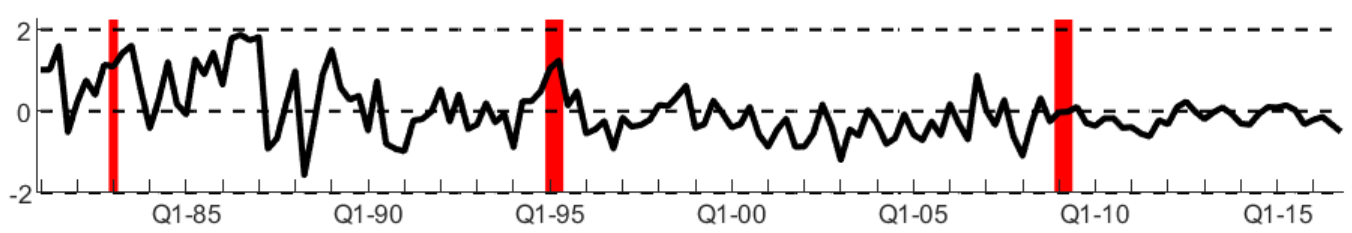

Notes: The figure plots the estimated model implied shocks, in standard deviation units, together with a two-standard deviations band (black dashed lines). Red bars indicate model-identified periods of crisis peak, see text for definition. 
Figure 9: Transition Probabilities

(a) Transition Probability of Binding Given Non-Binding

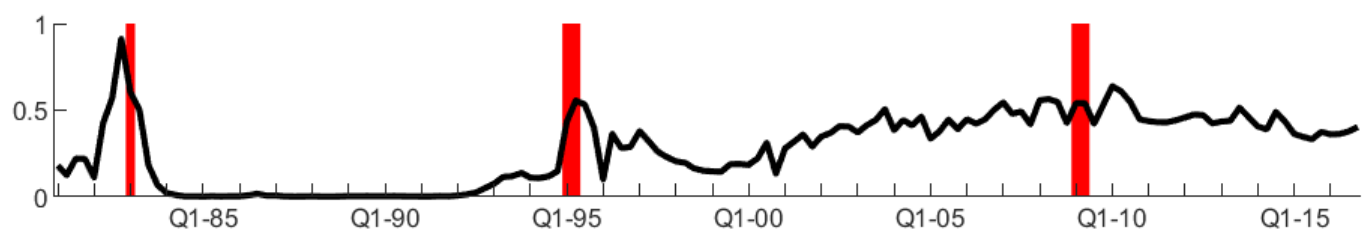

(b) Transition Probability of Non-Binding Given Binding

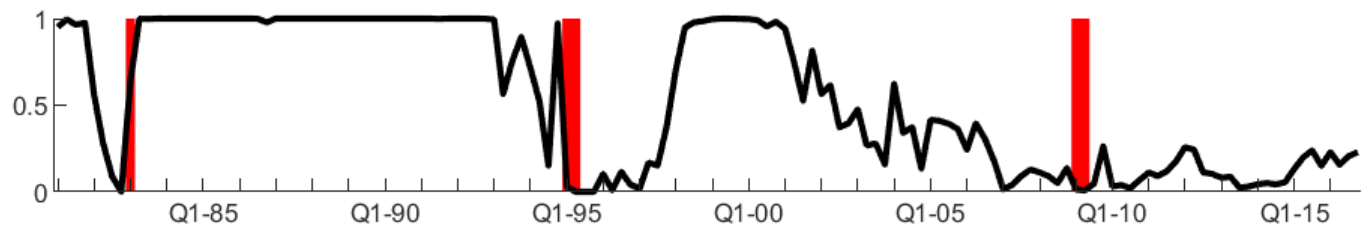

Notes: The top panel shows the model-implied filtered probability of transitioning into the binding regime in subsequent period, conditional on being in the non-binding regime in the current period. The bottom panel shows the filtered probability of transitioning to the non-binding regime, conditional on being in the binding regime. Red bars indicate model-identified crisis peaks defined in the paper.

misspecified.

\section{G.2 Assessing the Relative Importance of Shocks: A Likelihood- based Indicator}

To study the importance of shocks before, after and during financial crises episodes, we construct an indicator of relative importance of each shock. Let $L L$ denote the maximized log-likelihood over the full sample, and let $C L L_{i, t}$ denote the counterfactual full-sample log likelihood when shock $i$ is set to zero in quarter $t$ (i.e. $\varepsilon_{i, t}=0$ ). The loss of fit in likelihood points,

$$
\Delta_{i, t}=L L-C L L_{i, t}
$$

can be interpreted as an measure of importance of $\varepsilon_{i, t}$. Figure 10 shows how this measure evolves. There is an obvious shortcoming to this measure: since we are computing the difference in the likelihood over the full sample, earlier observations tend to have larger values of $\Delta_{i, t}$ due to the fact that they impact all subsequent quarters.

Hence, we focus on a relative importance measure. The importance of $\varepsilon_{i, t}$ relative 


\section{Figure 10: Historical Importance of Shocks, Log Points}

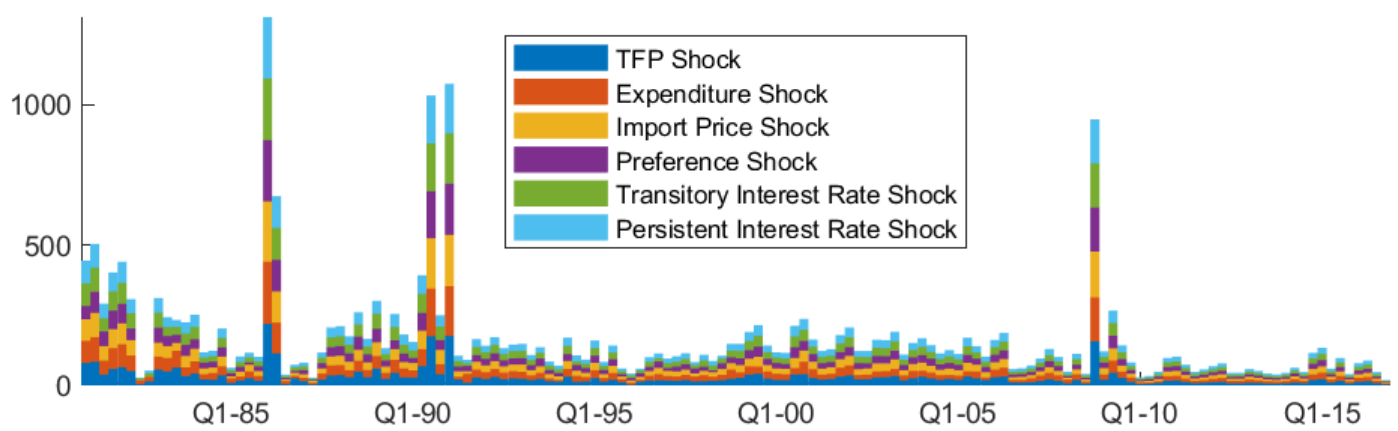

Notes: For each quarter, shows the likelihood contribution (in log points) for each shock, computed by setting the given shock to zero in the given quarter.

to other shocks at time $t$ can be assessed as

$$
\Lambda_{i, t}=\frac{\Delta_{i, t}}{\sum_{j} \Delta_{j, t}}
$$

where the denominator of this expression cumulates the the losses across all shocks. In the paper, we report this measure of relative importance in a given subsample period of $T$ quarters, $(t+T)-(t)$, compared to the full sample averages, $\bar{\Lambda}_{i}$. Thus, the subsample measure in the main text can be computed by $\sum_{t=t_{0}}^{t_{1}} \Lambda_{i, t}-\bar{\Lambda}_{i}$. Note here that, similar to our variance decomposition results, this calculation ignores the non-linearities captured by the second-order solution. 